A medição da capacidade criativa e cultural das cidades, um contributo para a sua operacionalização

\author{
Berta Rato \\ Pedro Costa \\ Bruno Vasconcelos
}

Dezembro de 2010

WP n. ${ }^{\circ} 2010 / 09$

DOCUMENTO DE TRABALHO

WORKING PAPER 


\title{
A medição da capacidade criativa e cultural das cidades, um contributo para a sua operacionalização
}

\author{
Berta Rato * \\ Pedro Costa $* *$ \\ Bruno Vasconcelos $* * *$ \\ WP n. ${ }^{\circ} 2010 / 09$ \\ Dezembro de 2010 \\ Revisto em Agosto de 2014
}

1. Introdução: a importância da medição da capacidade criativa e cultural das cidades.......3

2. Exemplos de metodologias para a medição da vitalidade cultural e criativa dos

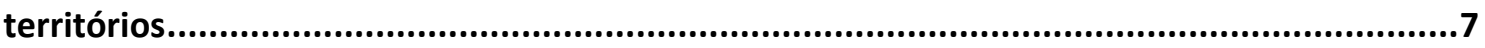

a) A viabilidade e vitalidade criativa da cidade segundo Landry e Bianchini ........................ 7

b) O "Local Culture Index", de Matarasso ............................................................................... 11

c) A abordagem aos índices de criatividade segundo o modelo de Florida........................ 14

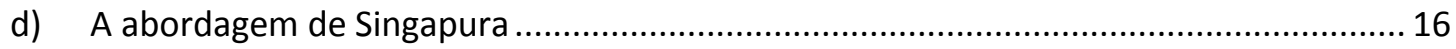

e) O Estudo "Creative Economy Report 2008 - The challenge of assessing the creative economy: towards informed policy making"

f) O projecto europeu ACRE - Accommodating Creative Knowledge - Competitiveness of European Metropolitan Regions within the Enlarged Union .............................................. 18

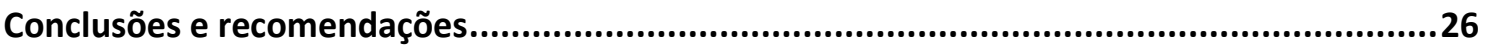

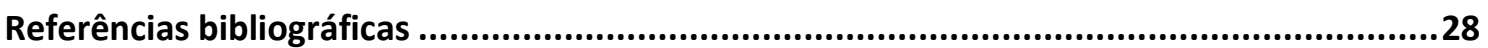

\footnotetext{
* University of Luxembourg.

** ISCTE e DINÂMIA'CET - IUL.

*** DINÂMIA’CET - IUL.
} 


\section{A medição da capacidade criativa e cultural das cidades, um contributo para a sua operacionalização ${ }^{1}$}

\section{Resumo:}

Este artigo visa apresentar uma proposta prática de operacionalização da medição da capacidade criativa e cultural das cidades. Não sendo esta uma questão pacífica (nem a própria medição em si nem os critérios que possam ser definidos para a sua consubstanciação) e levantando inúmeras dificuldades práticas, torna-se um desafio particularmente estimulante, mas também socialmente útil, numa época em que, quer no campo académico, quer no do policty-making, a pressão para a operacionalização de soluções pragmáticas para obviar a estas dificuldades se amplifica consideravelmente.

A nossa proposta de indicadores tem como ponto de partida, a análise crítica de propostas de indicadores de vários outros autores, incluindo propostas mais orientadas para os aspectos estritamente culturais, propostas centradas na criatividade e no conceito de talento, bem como estudos mais recentes com interessantes resultados ao nivel dos factores de localização e de atracção de recursos criativos. Num segundo momento, elenca-se uma bateria de indicadores potenciais, quase "ideal-tipicos", cobrindo de forma o mais exaustiva possível as várias dimensões de análise da criatividade. De seguida, com base num desafio lançado a toda a equipa de investigadores participantes no projecto em que se insere este artigo, é seleccionada uma "short-list", partindo da discussão e validação de uma lista sintética e operacional que reune até cerca de 20 indicadores-chave para a medição de dinâmicas culturais e criativas. Finalmente é discutida a pertinência da lista com base na identificação dos indicadores mais apontados.

\section{Palavras-Chave:}

Criatividade; Cidades Criativas; Índice de criatividade; Medição; Impactos; Urbano.

\footnotetext{
${ }^{1}$ Este paper foi preparado no âmbito do projecto de investigação CreatCity - "A governance culture for the creative city: urban vitality and international networks", conduzido pelo DINÂMIA-CET/ISCTE e financiado pela Fundação para a Ciência e a Tecnologia/Ministério da Ciência Tecnologia e Ensino Superior, com o apoio do FEDER e de fundos nacionais do MCTES (PTDC/AUR/65885/2006). Resulta igualmente em parte da investigação desenvolvida em paralelo pelos autores no âmbito de um outro projecto de investigação aplicada, realizado pelo DiINÂMIA-CET para a Câmara Municipal de Cascais: o Estudo sobre o potencial de desenvolvimento de Cascais com base nas Indústrias Criativas.
} 


\section{INTRODUÇÃO: A IMPORTÂNCIA DA MEDIÇÃO DA CAPACIDADE CRIATIVA E CULTURAL DAS CIDADES}

Este artigo visa apresentar uma proposta prática de operacionalização da medição da capacidade criativa e cultural das cidades. Não sendo esta uma questão pacífica (nem a possibilidade e as virtualidades da própria medição em si, nem os critérios, indicadores e dados empíricos que possam ser definidos para a sua consubstanciação) e levantando inúmeras dificuldades práticas, torna-se um desafio particularmente estimulante, mas também socialmente útil, numa época em que, quer no campo académico, quer no do policty-making, a pressão para a operacionalização de soluções pragmáticas para obviar a estas dificuldades se amplifica consideravelmente.

O discurso sobre a criatividade e o papel da cultura na vida das cidades não é novo. Desde as primeiras sociedades civilizadas da história da humanidade que está bem presente, ainda que nem sempre muito debatida, a questão da importância da cidade como palco de dinâmicas culturais e criativas entre agentes culturais, bem como o contributo desse ambiente para o desenvolvimento da cidade. Como nota P. Hall, a cidade sempre foi aliás o fulcro das dinâmicas criativas, ao longo da História (Hall, 2000), estando estas indelevelmente ligadas à sua vitalidade e ao seu desenvolvimento.

No contexto europeu, a cultura tem sido tradicionalmente encarada, de forma natural, mais como um fim a alcançar (por exemplo, através da actuação pública, ou da actuação de um promotor cultural) do que como um meio para alcançar um outro fim. Não defendemos que essa concepção "tradicional" não seja importante, fundamental mesmo, nem que essa deixe de ser uma (senão mesmo a) função primordial inquestionável da política pública no campo cultural. Contudo, observa-se ao longo dos anos mais recentes (e numa lógica não isenta de perigos vários...), que o discurso académico e as tendências do discurso político começam a situar o sector da cultura igualmente num outro lugar, nomeadamente com o crescente reconhecimento do seu potencial económico e de alavanca para o desenvolvimento urbano (nas suas diversas dimensões), e a cultura e a criatividade são agora encarados como motor das cidades e factor de desenvolvimento das regiões e do território (cf. a este propósito, por exemplo, Costa, 1997)

Apesar de todo o optimismo, à medida que são aprofundadas as investigações e desenhadas as primeiras estratégias, começam a emergir questões conceptuais, como por exemplo: o que é cultura? O que é criatividade? O debate destas questões e o posicionamento face às múltiplas cambiantes e perspectivas sobre estas noções é imprescindível para um amadurecimento sólido destas lógicas de criação de política e para o desenvolvimento de estratégias consequentes. Da mesma forma, a conceptualização da forma como a criatividade urbana pode ser determinante no seu desenvolvimento (e portanto, da sua articulação com as

DINÂMIA'CET - IUL, Centro de Estudos sobre a Mudança Socioeconómica e o Território ISCTE-IUL - Av. das Forças Armadas, 1649-026 Lisboa, PORTUGAL

Tel. 210464031 - Extensão 293100 E-mail: dinamia@iscte.pt www.dinamiacet.iscte.pt 
questões da competitividade e da vitalidade urbanas - cf Costa et al, 2009) é igualmente fundamental.

Em paralelo ao desenvolvimento de um campo conceptual balizado, necessário ao debate sobre a cultura e as suas possibilidades para as sociedades, emerge igualmente o debate sobre a cidade como espaço de excelência para sinergias entre agentes e a aposta por parte das autoridades locais e/ou regionais em iniciativas de apoio e de fomento da cultura e da criatividade.

No domínio das actividades culturais (e de certa forma da criatividade) os investimentos são até um certo limite um dado adquirido, uma obrigação do Estado, pelo menos nas zonas urbanas mais densas com níveis mínimos de procura (p.e., a existência de teatro, de centro cultural, de animação cultural). As decisões de intervenção, excepto no caso de grandes projectos com fortes expectativas de rendimento, não se baseiam (apenas) em análises de rentabilidade. Esta particularidade frequentemente determinou a quase inexistência de instrumentos para medição do contexto cultural e dos resultados de intervenções neste domínio.

No entanto, estas iniciativas à semelhança de outros domínios de intervenção pública requerem instrumentos de medição, quer por motivos de legitimização e de transparência quanto às escolhas em matéria de alocação de recursos, quer como forma de identificação de resultados das intervenções e de apoio à gestão.

Nas duas últimas décadas, o referido crescente reconhecimento da cultura e sobretudo das indústrias criativas como actividades económicas capazes de gerarem emprego e rendimentos tem levado ao repensar da importância de medir as actividades culturais e criativas (cf. p.e., OECD, 2005, 2006; KEA/CE, 2006, UNCTAD/UNDP, DCMS 1998, 2006, NESTA, 2006). Em termos mais pragmáticos, a contabilização destas actividades serve propósitos diversos de acordo com a fase do ciclo de vida de uma nova iniciativa:

- Como fonte de informação para um diagnóstico mais detalhado do sector cultural e criativo, útil para identificação do potencial neste domínio, nomeadamente em comparação com outros territórios, e consequentemente para apoio à decisão de se lançar ou não uma estratégia de desenvolvimento do mesmo;

- Como meio de suporte a uma estratégia coerente e fundamentada, com objectivos concretos e realizáveis, tendo em vista o desenvolvimento do sector;

- Como base para a criação de um sistema de monitorização e de avaliação dos recursos culturais e criativos de um território;

- Como forma de medir os resultados e os impactos de políticas de investimento no sector ou de certos projectos, fundamental, primeiro, num contexto de recursos escassos e de procura de eficiência na aplicação de recursos; segundo, como forma de validação ou de infirmação da pertinência da estratégia, podendo eventualmente resultar em reorientações da mesma;

DINÂMIA'CET - IUL, Centro de Estudos sobre a Mudança Socioeconómica e o Território ISCTE-IUL - Av. das Forças Armadas, 1649-026 Lisboa, PORTUGAL

Tel. 210464031 - Extensão 293100 E-mail: dinamia@iscte.pt www.dinamiacet.iscte.pt 
- Como forma de promoção do debate em torno da contribuição da cultura e da criatividade para o desenvolvimento económico local e para a criação de emprego.

Apesar da importância da aferição do papel das actividades culturais e criativas e da construção de indicadores objectivos para a monitorização e a avaliação de impactos e resultados, a recolha desta informação e a constituição de bases de dados apresenta diversas dificuldades. Em primeiro lugar, porque não existe uma definição universal de quais as indústrias culturais e criativas a considerar como objecto da intervenção - mesmo análises realizadas no mesmo país apresentam diferenças na definição do sector criativo. Por outro lado, a informação estatística oficial na maior parte dos países não dá resposta às necessidades, ou por não oferecer dados a nível local, ou por não existirem séries longas para medição da evolução, ou pela debilidade dos dados existentes (num sector com peso significativo da informalidade, do auto-emprego, da actividade a tempo parcial, da actividade não remunerada ou voluntária, da diluição produçãoconsumo, etc.), ou, ainda a título exemplificativo, por a maior parte das dimensões de análise não ser contemplada nas estatísticas oficiais, sobretudo no domínio das dimensões de carácter mais qualitativo, completamente excluídas.

Como consequência, a maior parte dos estudos empíricos sobre o potencial e a evolução da criatividade de um território assenta num conjunto reduzido de indicadores mais facilmente contabilizáveis, tais como: o volume de emprego, o número de estabelecimentos dos diversos ramos culturais e criativos, o volume de negócios, os gastos públicos com a cultura, as audiências de espectáculos, as visitas a equipamentos culturais, os direitos de autor e de propriedade intelectual (na generalidade dos casos, com limitações muito graves ao nível da sua qualidade). Em estudos mais aprofundados implementados em territórios mais circunscritos tem-se ido mais além, recolhendo-se informação complementar por meio de instrumentos de inquirição. No entanto, dado os custos elevados de tais processos, dificilmente estes poderão ser apropriáveis de forma mais generalizada por outros territórios ou para a globalidade de territórios mais vastos.

É neste contexto de pertinência da contabilização das actividades culturais e criativas mas de insuficiência da informação efectivamente disponível que importa pensar um conjunto de indicadores que possam obviar a esse problema de forma eficiente. A selecção deste tipo de indicadores deverá seguir portanto os princípios commumente aceitáveis: serem específicos, mensuráveis, obteníveis, relevantes e passíveis de obtenção regular e atempada (SMART Specific, Measurable, Attainable, Relevant, Timely). Mas por outro lado, deve ser operacionalizável, isto é o número de indicadores deverá ser limitado mas representativo das várias dimensões de análise. Finalmente, deverá permitir a sua comparabilidade, no tempo,

DINÂMIA'CET - IUL, Centro de Estudos sobre a Mudança Socioeconómica e o Território ISCTE-IUL - Av. das Forças Armadas, 1649-026 Lisboa, PORTUGAL 
naturalemnte, mas também no espaço, e não só a nível nacional (ou dentro de um mesmo sistema de estatístico), mas, idealmente, além fronteiras.

O nosso contributo para uma proposta de indicadores, que se operacionaliza nas secções eguintes, tem como ponto de partida a análise crítica de outras propostas de indicadores, de vários autores, incluindo propostas mais orientadas para os aspectos estritamente culturais, propostas centradas na criatividade e no conceito de talento, bem como estudos mais recentes com interessantes resultados ao nivel dos factores de localização e de atracção de recursos criativos. Num segundo momento, apresenta-se uma bateria de indicadores potenciais, cobrindo de forma o mais exaustiva possível as várias dimensões de análise da criatividade. De seguida, e partindo do desafio efectuado a toda a equipa do nosso estudo para a discussão e a validação de uma lista sintética e operacional de indicadores-chave para a medição de dinâmicas culturais e criativas. que não deveria ultrapassar os 20 indicadores,faz-se uma operacionalização mais limitada de indicadores-chave, com base na identificação dos indicadores mais apontados pelo colectivo e na discussão da pertinência da lista. 


\section{EXEMPLOS DE METODOLOGIAS PARA A MEDIÇÃO DA VITALIDADE CULTURAL E CRIATIVA DOS TERRITÓRIOS}

Não obstante as condicionantes da construção e aplicação de baterias de indicadores para a medição das actividades culturais e criativas, vários autores e instituições procuraram ir mais além e ensaiaram instrumentos, com base numa bateria de indicadores mais extensa, com o propósito de diagnosticar o potencial criativo de uma cidade. Apresenta-se de seguida um conjunto (que se procurou diverso, abrangente e plural) de experiências recolhidas na literatura recente, as quais procuraram dar resposta a estes desafios: as análises de Matarasso e de Landry e Bianchini (realizadas no seio da Comedia, entidade que há vários anos analisa o papel das actividades criativas no desenvolvimento urbano, no Reino Unido e noutros países); o muito popularizado e mediatizado quadro de análise de Richard Florida; um estudo mais assente numa perspectiva mais "macro", sobre as indústrias criativas em Singapura; a análise realizda no âmbito das Nações Unidas pela UNCTAD; e, finalmente, a reflexão realizada no âmbito de um projecto de investigação europeu em larga escala, o ACRE. Qualquer destas abordagens permitiu a construção de um quadro de trabalho que estabelece um certo número de indicadores com o propósito de diagnosticar (embora uns de forma mais crítica que outros) o potencial criativo de uma cidade.

\section{a) A viabilidade e vitalidade criativa da cidade segundo Landry e Bianchini} (Landry, C. e Bianchini, F. (1994))

No âmbito da análise de autores ligados à britânica Comedia, Landry e Bianchini estabelecem critérios para medir a viabilidade e a vitalidade cultural e criativa da cidade, apontando indicadores que passam por uma definição prévia do que são os recursos culturais e criativos de uma cidade. Se por um lado, os recursos culturais de uma cidade se associam a elementos como a população local e a sua capacidade criativa, património, identidade, gama de produtos produzidos ao nível local, património edificado, atractividade, etc., os recursos criativos caracterizam-se igualmente pelo seu carácter experimentalista e inovador, pela sua originalidade, pela capacidade de reorganizar regras, gerar comportamentos alternativos, etc.

No entanto, para além da discussão sobre cultura e criatividade e a sua distinção, revelase importante perceber o que caracteriza as noções de vitalidade e viabilidade das cidades, bem como perceber a relação destas noções com a sua capacidade criativa e cultural. Isto porque a noção de viabilidade nos remete para as ideias da sustentabilidade, adaptabilidade, flexibilidade, capacidade auto regenerativa, responsabilidade e segurança das cidades. Estes aspectos estão fundamentalmente relacionados com o carácter cultural e criativo das comunidades, seja do ponto vista da população, seja da massa crítica, seja da postura política do poder local. As 
cidades são comparáveis a organismos vivos, com períodos de crescimento, estabilização e declínio. A capacidade de resposta das cidades para os novos desafios, passa fundamentalmente pela sua capacidade de sustentabilidade e de renovação de paradigmas que permitam o rejuvenescimento da vida da cidade. Por isso, uma cidade que reconheça a importância das noções de viabilidade e vitalidade, reconhece em si quais os factores capazes de potenciar o seu carácter cultural e criativo, como ferramentas de sustentabilidade, de valorização e competitividade do território. Dado isto, é possível atribuir alguns critérios que permitem medir a viabilidade e vitalidade das cidades, os quais são expressos na tabela seguinte:

Tabela 1. Indicadores de Viabilidade e Vitalidade das Cidades (para Landry e Bianchini, 1994)

Massa Crítica (Nível mínimo de recursos)

\section{Diversidade (A ideia da diversidade vai aumentar o leque de possibilidades de uma cidade. Quanto maior o número de possibilidades, mais facilidade a cidade poderá ter em adaptar-se)}

Acessibilidade ( $A$ acessibilidade permite a identificação e exploração de recursos criativos)

\section{Níveis}

a. Ao nível económico: Passa pela ideia da existência de um aglomerado de agentes que facilitem a emergência de economias de escala, cooperação e sinergias entre agentes, a existência de um distrito financeiro no centro da cidade, a existência de bairros artísticos dentro da cidade, um parque tecnológico fora da cidade. Representa ainda a existência de organizações com iniciativas económicas como feiras de negócios, missões de trocas externas, etc.

b. Ao nível social: Pode entender-se pela densidade de relações sociais em determinadas zonas da cidade, em diferentes momentos cronológicos (hora dia, dias da semana, meses).

c. Ao nível do ambiente e envolvente: Numa cidade atractiva, deve existir mais do que um ponto atractivo no que concerne à massa crítica (museus, restaurantes, espaços verdes qualificados). Pode existir em diferentes localizações da cidade: centro, perto do centro ou subúrbios, uma massa crítica sob a forma de edifícios históricos em número suficiente para constituir de zonas históricas, o mesmo é aplicado a espaços verdes, existência de rios nas zonas periféricas, etc.

d. Ao nível cultural: Engloba história, imagem (representações e identidade), redes de espaços públicos. Existência de participação da comunidade nos debates e discussões na definição de uma agenda de eventos coerente. A massa crítica cultural é também a existência de soluções diferentes e grande diversidade de oferta cultural.

e. Ao nível económico: Diversidade de economias, considerando as economias especializadas existentes, que necessitam ser encorajadas. Neste caso, o planeamento tem um papel crucial para desenvolver a diversidade económica e aumentar a capacidade de adaptação da cidade.

f. Ao nível social: Cosmopolitismo e vivacidade da sociedade civil e existência de um grande sector voluntário; existência de organizações com grande nível de confiança capazes de gerir situações de mudança; utilização do multiculturalismo como elemento fulcral para a renovação das ideias e da criatividade.

g. Ao nível cultural: Implica o estímulo para oportunidades de produção, consumo e distribuição. Promover a ideia do que é a cultura local.

h. Ao nível ambiente e envolvente: Passa pela diversidade dos espaços naturais que a cidade oferece bem como dos espaços construídos, constituindo uma heterogeneidade de comunidades.

i. Ao nível económico: Oportunidade de participação na vida económica através da existência de serviços de aconselhamento, tecnologia, fontes de informação, formação e capital de risco. Ter acesso à economia ajuda na renovação da cidade.

j. Ao nível social: Fazer parte, ter acesso à vida da cidade. Fazer de todos os cidadãos, grupos sociais, elementos activos na vida da cidade, seja na participação directa na tomada de decisões, seja pelo uso dos equipamentos existentes.

k. Ao nível ambiente e envolvente: Passa pela existência de uma rede de transportes públicos inclusiva para as diferentes áreas geográficas da cidade, a existência de parques de estacionamento eficientes, acessos de carro e segurança. Existência de WCs, nos espaços públicos, existência de pontos informativos sobre a cidade em lugares de entrada. 


\begin{tabular}{|c|c|c|}
\hline $\begin{array}{l}\text { Segurança } \\
\text { (Apesar de ao } \\
\text { processo criativo } \\
\text { estarem } \\
\text { associados } \\
\text { ambientes } \\
\text { depressivos, um } \\
\text { clima criativo só } \\
\text { consegue } \\
\text { florescer num } \\
\text { ambiente seguro } \\
\text { e calmo). }\end{array}$ & & $\begin{array}{l}\text { Ao nível económico: Estabilidade da base económica local, do ponto de vista das } \\
\text { empresas e dos trabalhadores. Compromisso das empresas com o território, } \\
\text { investimento visível das empresas confere segurança. } \\
\text { Ao nível social: Inexistência de ameaças para pessoas e propriedades, } \\
\text { sentimento de confiança e união entre os cidadãos, existência, apoio e } \\
\text { solidariedade de redes como centros de aconselhamento, policiamento } \\
\text { comunitário. A mistura de utilizações em termos de idades, hora do dia aumenta o } \\
\text { nível de negócio na cidade e contribui para o sentimento de segurança. } \\
\text { Ao nível ambiente e envolvente: Limpeza da cidade, policiamento, espaços } \\
\text { cuidados e não esquecidos. } \\
\text { Ao nível cultural: Implica a aceitação de toda a diversidade cultural. A existência } \\
\text { de festivais e celebrações culturais diversas, reafirmando e reinventando a } \\
\text { identidade da cidade, ou de um bairro, enquanto um todo confere sensação de } \\
\text { segurança. A segurança é garantida se houver liberdade de expressão, ter acesso } \\
\text { a espaços de eventos, financiamentos e informação. }\end{array}$ \\
\hline $\begin{array}{l}\text { Identidade e } \\
\text { distinção } \\
\text { (Permitem } \\
\text { perceber quais } \\
\text { são os pontos } \\
\text { fortes de uma } \\
\text { comunidade que } \\
\text { podem e devem } \\
\text { ser potenciados. } \\
\text { É na diversidade } \\
\text { das diferentes } \\
\text { culturas e } \\
\text { comunidades da } \\
\text { cidade, que se } \\
\text { pode encontrar o } \\
\text { ponto comum } \\
\text { para a } \\
\text { cooperação no } \\
\text { sentido de apoiar } \\
\text { o bem comum } \\
\text { que é a cidade.) }\end{array}$ & S. & $\begin{array}{l}\text { mico: A expansão dos efeitos da globalização e da tendência para } \\
\text { ção das cidades sugere a potencialização das características } \\
\text { território que são valorizadas por não existirem noutras cidades. } \\
\text { stimulado, incentivando as empresas locais a imprimirem a sua } \\
\text { dade. } \\
\text { I: Estas dimensões facilitam a existência de um orgulho cívico, } \\
\text { unidade e preocupação com o ambiente urbano. Por outro lado, a } \\
\text { árias identidades culturais exige que exista um ambiente inclusivo } \\
\text { ade para que a cidade funcione de uma forma una e não } \\
\text { ural: Encorajamento para a manutenção e demonstração das } \\
\text { turais locais (gastronomia, música, dialectos, artesanato, outras } \\
\text { gualmente importante, a criação de novas tradições e imagens e } \\
\text { ação da identidade da cidade. } \\
\text { nte e envolvente: As cidades históricas têm a vantagem de terem } \\
\text { elementos físicos, edifícios, monumentos, etc., que relatam a } \\
\text { tória da cidade. Por outro lado, as novas cidades devem recorrer } \\
\text { de artistas para o desenvolvimento de trabalho criativo à volta da } \\
\text { unidade, sobre o passado, presente ou futuro, criando ambientes } \\
\text { oanos com identidade e distintos. }\end{array}$ \\
\hline $\begin{array}{l}\text { lade } \\
\text { ra } \\
\text { te }\end{array}$ & & $\begin{array}{l}\text { nível económico: A existência de um ambiente criativo inovador é a chave } \\
\text { a tornar uma cidade economicamente viável. A cidade deve promover a } \\
\text { ecialização, I\&D, promover o aparecimento de empresas inovadoras. A cidade } \\
\text { e favorecer a emergência de ideias e investimentos inovadores, criando } \\
\text { rtunidades para todos. } \\
\text { nível social: Consulta da arena social relativamente às decisões tomadas pelo } \\
\text { ler local. Transparência nos procedimentos e estratégias. Permitir o debate } \\
\text { lico das decisões. Ambiente sócio político que viabilize as opiniões das } \\
\text { iorias, bem como das minorias. } \\
\text { nível cultural: Políticas que apoiem actividades artísticas experimentais e } \\
\text { neiras. Apoio a projectos que liguem o passado da cidade com o futuro. } \\
\text { olvimento das comunidades artísticas na imagem que a cidade dá ao mundo } \\
\text { erior. Cooperação entre diferentes sectores criativos (sector dos media e } \\
\text { nologia, e estúdios de gravação, por exemplo). Ambiente inovador que permita } \\
\text { artistas expandirem as suas actividades para outros espaços contribuindo para } \\
\text { uzir o stress social (prisões, instituições para os sem abrigo). } \\
\text { nível ambiente e envolvente: Existência de projectos que prevejam a } \\
\text { anização física da cidade e dos bairros. Existência de projectos que envolvam } \\
\text { stas/ designers e planeadores/ engenheiros. Existência de projectos ambientais } \\
\text { n soluções ao nível dos transportes, reciclagem e de espaços verdes. }\end{array}$ \\
\hline
\end{tabular}

DINÂMIA'CET - IUL, Centro de Estudos sobre a Mudança Socioeconómica e o Território ISCTE-IUL - Av. das Forças Armadas, 1649-026 Lisboa, PORTUGAL 
Cooperação e sinergias

( $A$ abertura da cidade ao mundo exterior é um ponto crucial para alcançar um bom fluxo de ideias e de informação. Por outro lado, é importante que a cidade tenha uma boa relação com a sua identidade para não ser colonizada por culturas exteriores em detrimento da sua própria cultura.)

\section{Competitividade (Um dos papeis do pensamento criativo é potenciar a cidade nas suas características e torna-la competitiva)} organizacional (Papel do poder local e instituições) x. Ao nível económico: É desejado um elevado nível de cooperação dentro do território. O papel das empresas no desenvolvimento do território e das diferentes zonas da cidade. O centro da cidade é muitas vezes a ligação entre a economia local e o mundo exterior. A capacidade de estabelecer relações é importante para o crescimento de economias internacionais e das economias urbanas considerando a importância crescente das políticas da EU para as cidades na competitividade inter-urbana. Ter uma raiz local, mas um papel internacional é um factor chave para a vitalidade urbana e a existências de redes inter-regionais são uma condição para o sucesso das redes internacionais urbanas. Quanto mais cooperação existir numa cidade maior o compromisso existente das empresas com o seu território e maior o investimento das empresas.

y. Ao nível social: A cidade também beneficia das redes sociais. O centro funciona como o ponto de contacto e comunicação entre diferentes grupos sociais representando a imagem do todo da cidade. A existência de estratégias de internacionalização destas relações sociais é um ponto favorável.

z. Ao nível cultural: $O$ centro da cidade não deve ser o único ponto de infraestruturas culturais, mas deve haver uma dispersão por todas a zonas da cidade. O centro deve funcionar como o espaço de exposição do que melhor se faz na cidade. O centro da cidade é também o espaço onde é possível encontrar os serviços de mercado e de distribuição de produtos, performances e artefactos. Por fim, é também no centro que é possível encontrar elementos exteriores como jornais estrangeiros e livros, bem como o espaço onde se realizam as celebrações de toda a cidade.

aa. Ao nível ambiente e envolvente: É importante destacar a ligação do centro às diversas zonas da cidade, havendo dessa forma uma relação física. Evitar barreiras físicas que não permitam a fluidez de comunicação entre diferentes zonas da cidade

bb. Ao nível económico: Nível de lucro, investimento, inovação tecnológica e acesso a capital de risco por empresas a funcionar dentro da cidade. Nível de qualificações dos trabalhadores bem como ao nível da comunicação, qualidade das infra-estruturas de comunicação. Status das empresas ao nível nacional e internacional.

cc. Ao nível social: Qualidade das relações sociais (inter-racial, por exemplo) bem como do sector voluntário.

dd. Ao nível ambiente e envolvente: Está relacionado com a singularidade e atractividade da paisagem da cidade (natural, urbana) bem como da sua localização e ligações existentes.

ee. Ao nível cultural: Posição e status das instituições e actividades educativas e culturais e como são vistos por outros parceiros.

ff. A todos os níveis: Capacidade para o poder local, nas suas diversas vertentes de desenvolver a capacidade de implementar ideias e iniciativas criativas. A capacidade de organizar é um ponto fundamental para viabilizar uma cidade. Capacidade de liderar, ser tecnicamente competente e estar actualizado, identificar estratégias e prioridades, ter uma visão a longo prazo, ouvir e consultar outros, ganhar a lealdade, confiança, inspirar e entusiasmar outros agentes com poder de decisão. É importante a existência de uma equipa com uma identidade de cooperação forte.

Fonte: elaboração própria, a partir dos autores 
A principal mais-valia desta proposta de indicadores é o seu carácter holístico, englobando todas as dimensões da cultura e da criatividade, sobretudo os aspectos sociais e ambientais, que nalgumas intervenções mais orientadas para objectivos económicos ou em grandes projectos culturais têm vindo a ser descurados, traduzindo-se em alguns casos na rejeição por parte da população local e consequente necessidade de revisão do projecto (p.e., no caso da operação de revitalização urbana22@, em Barcelona).

Por outro lado, a consideração dos critérios "massa crítica" e "diversidade", que aparecem no topo dos diversos critérios, parece-nos igualmente muito importante, na medida em que permite logo no início da análise ter uma ideia sobre a infraestrutura geral de enquadramento do sector.

Menos operacionalizável parece-nos a possibilidade de medição e a apreciação de várias componentes de carácter qualitativo, como evidenciado por exemplo por "Qualidade das relações sociais" ou a "Capacidade de organizar", bem como a possibilidade de comparação com outros territórios ou as dificuldades em medir a evolução temporal dos diversos indicadores. Estas limitações estarão, contudo, na origem da não aplicação prática desta grelha de análise.

\section{b) O "Local Culture Index", de Matarasso}

(F. Matarasso, 1999)

O Local Culture Index proposto uns anos mais tarde, diferencia-se do anterior, primeiro pelo seu enfoque prioritário nas actividades culturais e menos nas actividades criativas em sentido mais lato; segundo, pelo seu objectivo de maior operacionalidade, a criação de um instrumento que permitisse às autoridades locais calcular o nível de apoios às actividades culturais e a "vitalidade cultural" de um terrritório. O índice poderia ser também utilizado como meio de comparação com a situação de outros municípios ou cidades.

Este índice orienta-se, pois, para o desenvolvimento comunitário e não tanto para o desenvolvimento económico. No entanto, os artistas profissionais de todos os tipos, com actividade "comercial", são também incluídos, atendendo a que, por um lado, contribuem de forma significativa para a dinamização local mas, por outro lado, são também um indicador da própria animação urbana.

Matarasso define o Local Culture Índex com base em três linhas de análise:

- Inputs - condições e recursos que a cidade tem para enraizar e nutrir as actividades e o dinamismo culturais;

- Outputs - resultados directos da utilização desses recursos em actividades criativas, consubstanciados na concretização de actividades e no dinamismo cultural:

- Resultados (Outcomes) - impactos que os resultados destas actividades têm directamente na vida da cidade e das suas comunidades.

DINÂMIA'CET - IUL, Centro de Estudos sobre a Mudança Socioeconómica e o Território ISCTE-IUL - Av. das Forças Armadas, 1649-026 Lisboa, PORTUGAL

Tel. 210464031 - Extensão 293100 E-mail: dinamia@iscte.pt www.dinamiacet.iscte.pt 
A tabela seguinte apresenta uma síntese dos indicadores que este autor sugere para a monitorização destas três linhas de análise:

Tabela 2. Indicadores de Cultura e Criatividade "Comercial" de um território (segundo Matarasso, 1999)

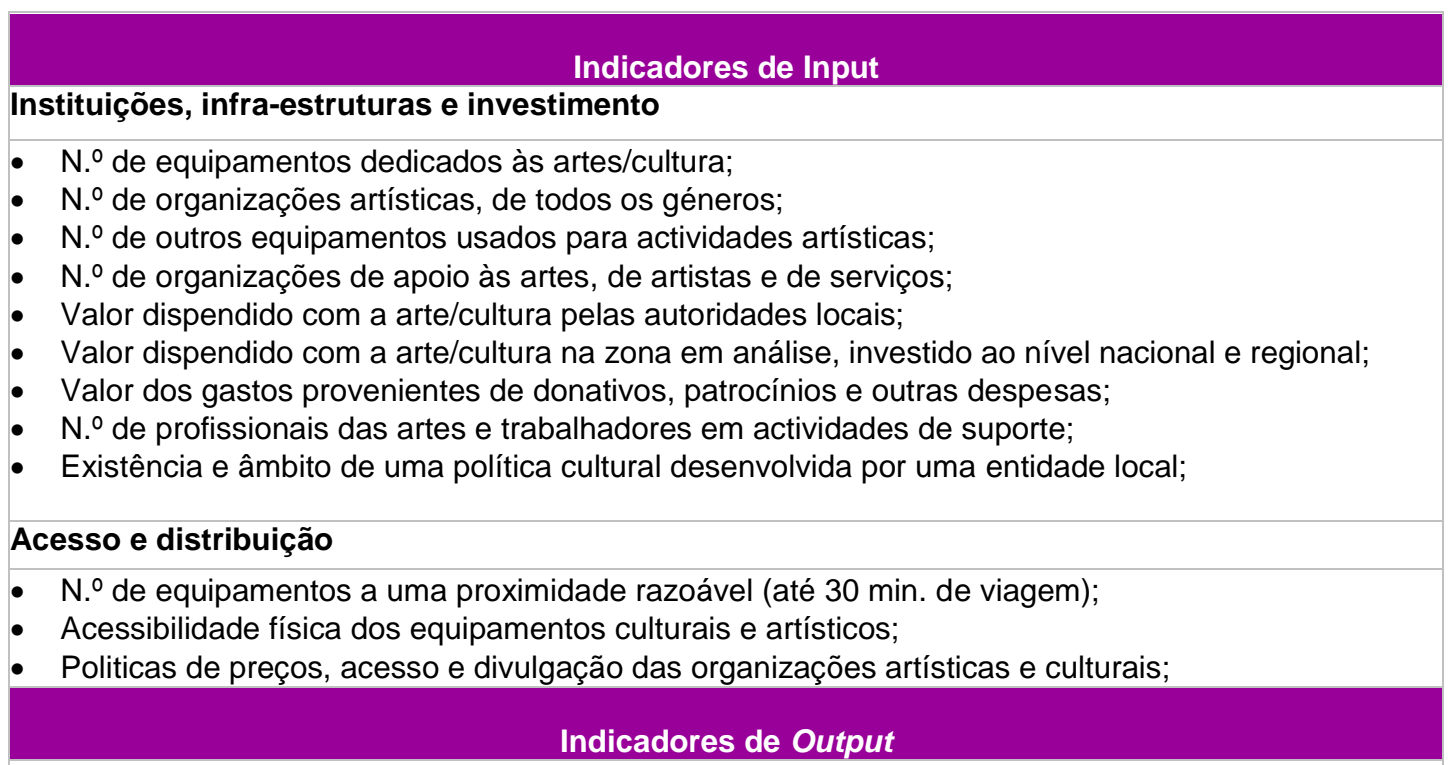

\section{Actividades e participação}

- $\quad \mathrm{N} .$. o de performances, eventos, dias de exibição, workshops, etc.;

- N. de novas comissões, produções e trabalhos de arte pública;

- $\quad$ ․o de visitantes nestes eventos;

- Capacidade média para os diferentes tipos de actividade;

- Proporção das actividades que é independente de subsídios;

- N. de membros de grupos artísticos comunitários ou voluntários, e o n.ำ de grupos iniciados ou extintos em cada ano;

- Extensão da participação individual em actividades culturais (p.e., em aulas ou grupos);

\section{Diversidade}

- Diferentes tipos de tradições culturais localmente activas;

- Extensão do apoio público às diferentes formas e expressões culturais;

- Composição dos públicos, para diferentes actividades;

- Extensão das ligações e cooperação entre diferentes tradições culturais;

\section{Educação e Formação}

- N. de professores, formadores e profissionais de educação artística;

- Quantidade de actividades artísticas apoiadas através das escolas (em regime curricular ou extra curricular);

- A natureza e extensão das actividades artísticas de nível terciário, incluindo o n.ำ de pessoas a estudar para qualificações artísticas;

- Envolvimento na educação pelas organizações artísticas do sector público;

\section{Actividade criativa comercial}

- N. ${ }^{\circ}$ de artistas e "artesãos" residentes;

- $\quad \mathrm{N}$. ․ e tipos de indústrias criativas locais;

- $\quad \mathrm{N}$. . de recintos e equipamentos de arte comercializável;

- Rendimento e emprego combinados do sector cultural local;

DINÂMIA'CET - IUL, Centro de Estudos sobre a Mudança Socioeconómica e o Território ISCTE-IUL - Av. das Forças Armadas, 1649-026 Lisboa, PORTUGAL

Tel. 210464031 - Extensão 293100 E-mail: dinamia@iscte.pt www.dinamiacet.iscte.pt 


\section{Desenvolvimento Pessoal}

- Reforço dos níveis de auto confiança;

- Vida social mais activa;

- Maior envolvimento nas actividades da comunidade;

- Aproveitamento da formação na comunidade e da formação vocacional e da educação;

- Valorização da auto-imagem e auto-representações;

- Reforço do entendimento dos direitos e das responsabilidades;

- Identificação de novas capacidades;

- Criação de emprego e auto-emprego;

\section{Desenvolvimento da comunidade}

- Contacto inter-geracional; Cooperação intra-comunitária;

- Aumento da utilização do centro da cidade;

- Aumento da sensação de segurança;

- Empowerment e capacitação da comunidade;

- $\quad \mathrm{N}$. . de pessoas envolvidas em actividades da comunidade;

- Desenvolvimento de capacidades e competências organizativas;

- Desenvolvimento de novos projectos comunitários;

- Participação da população nas consultas locais;

- Melhoria na imagem dos bairros;

- Melhorias ambientais;

- Audiência das actividades artísticas;

- Reforço da sensação de bem-estar pessoal;

- Apoio a grupos vulneráveis;

- Valorização do trabalho voluntário.

Fonte: elaboração própria, a partir dos autores.

O maior mérito desta abordagem terá sido a tentativa de medir de forma sistematizada as diversas facetas das actividades culturais e criativas numa dada comunidade, em particular dando relevo às dimensões social e qualidade urbana. Por outro lado, o processo de inventariação assentava num forte envolvimento da população, com impactos positivos no debate e no reforço do reconhecimento do valor da cultura e da criatividade ao nível local .

No entanto, este instrumento desde logo revelou diversas fragilidades, também reconhecidas pelo autor, sobretudo as dificuldades efectivas de operacionalização do mesmo - a dificuldade de contabilização dos vários indicadores, sobretudo de natureza qualitativa ou a não existência de uma hierarquia clara de indicadores.

Do nosso ponto de vista, entre as principais limitações deste índice estão, por um lado, o facto de este não se tratar efectivamente de um índice mas de uma inventariação de indicadores, sendo practicamente impossível obter um valor sintético ou um valor médio base para comparação entre diferentes territórios; e por outro lado, a impossibilidade de ser utilizado para medir a evolução do panorama das actividades culturais e, embora com menor peso, também das actividades criativas - apesar de se proporem indicadores de resultados, na realidade, a maior parte destes apenas permite uma análise de contexto e não propriamente a medição da evolução.

DINÂMIA'CET - IUL, Centro de Estudos sobre a Mudança Socioeconómica e o Território ISCTE-IUL - Av. das Forças Armadas, 1649-026 Lisboa, PORTUGAL

Tel. 210464031 - Extensão 293100 E-mail: dinamia@iscte.pt www.dinamiacet.iscte.pt 
Por outro lado, como a própria designação do indicador aponta o enfoque é sobretudo nas actividades culturais, nesta abordagem as outras actividades "criativas" ficam excluídas da análise. Na prática, e apesar de condições relativamente óptimas no Reino Unido para a aplicação deste instrumento (p.e., existência de excelentes estatísticas ao nível local, diversidade de cidades com políticas de promoção da criatividade), não foi possível convencer as autoridades locais, com excepção de algumas experiências pontuais, a testarem de forma mais sistemática estes indicadores.

\section{c) A abordagem aos índices de criatividade segundo o modelo de Florida}

(e.g. R. Florida, 2002; Florida and Tinagli, 2004; Tinagli et al, 2007)

A análise de Richard Florida tem sido muito utilizada, e o seu contributo muito citado quando se fala de tentar medir a criatividade das cidades e regiões e tentar encontrar índices que permitam estudos comparativos. O seu modelo e análise empírica, originalmente aplicado aos EUA (Florida, 2002), foi posteriormente adaptado ao estudo da Europa em geral (Florida e Tinagli, 2004), ou em diversos outros países, em análise mais detalhadas. Um desses exemplos, que assumimos como ilustrativo destas abordagens é o do estudo realizado na Suécia pela School of Business, Economics and Law, da Universidade de Göteborg (em conjunto com o Creativity Group Europe, de Florida), denominado "Sweden in the Creative Age", essencialmente recorrendo ao índice proposto por este autor para "medir" o nível criativo de diversas cidades suecas. Florida define o modelo dos "três T's": Tecnologia, Talento e Tolerância, os quais representam as dimensões consideradas como fulcrais para explicar a criatividade de certas cidades. Cada uma destas dimensões é analisada por uma bateria de indicadores que, de uma forma inter-relacionada, acabam por revelar a capacidade criativa de uma cidade: ou seja, para estes autores, a sua capacidade de gerar ou de atrair a criatividade (e os recursos humanos, tecnológicos e organizacionais criativos). Esta abordagem acaba por se basear, num cenário de grande mobilidade residencial como o dos EUA, essencialmente na averiguação da presença de classes criativas na cidade e na capacidade que estas mostram de atracção de classes criativas.

$\mathrm{Na}$ tabela seguinte apresentam-se os indicadores utilizados para a medição das dimensões 3 T's no caso concreto da Suécia, que assumimos como paradigmático deste tipo de abordagens.

DINÂMIA'CET - IUL, Centro de Estudos sobre a Mudança Socioeconómica e o Território ISCTE-IUL - Av. das Forças Armadas, 1649-026 Lisboa, PORTUGAL 
Tabela 3. Indicadores para Medição das Dimensões “3 T's” (Tinagli et al, 2007)

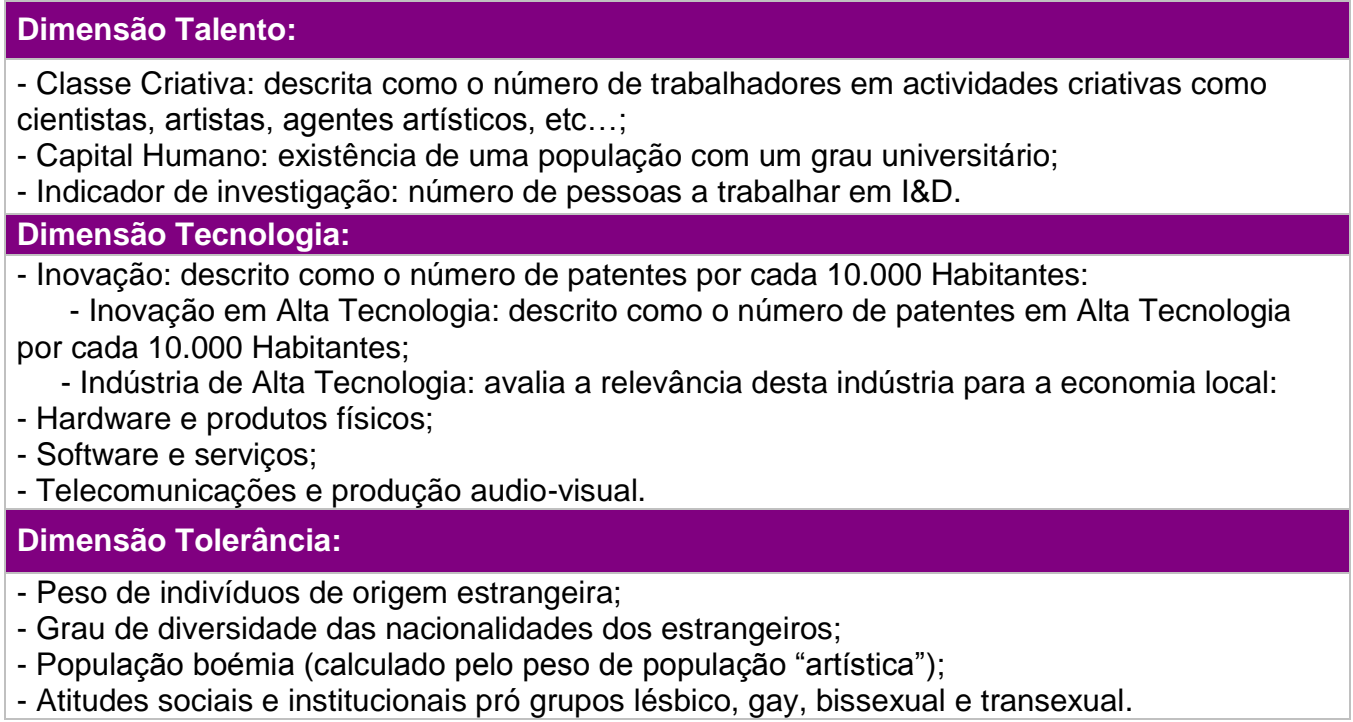

Fonte: elaboração própria, a partir dos autores.

O grande impacto da abordagem de Florida e empresas de consultoria associadas, relaciona-se com os seus contributos, que passam, em primeiro lugar, pela sua relativa simplicidade de cálculo, permitindo a criação de índices de criatividade e posteriormente a criação de rankings de cidades e a possibilidade de benchmarking ao nível das indústrias criativas. Florida contribuiu ainda para uma actualização dos ramos a considerar como criativos (numa visão muito ampla, muito para além do campo das actividsades culturais), adaptando-os à economia actual. Por exemplo, sectores como os multimédia ou a a informática são igualmente incluídos nas estatísticas utilizadas por estes autores. Finalmente, deve-se a Florida o reforço da ideia da criatividade como factor de desenvolvimento urbano e, na prática, a utilização da retórica das indústrias criativas como base para a implementação de estratégias de desenvolvimento das cidades centradas na atractividade.

Apesar do indiscutível impacto dos conceitos e da metodologia de Florida, aplicada um pouco por todo o mundo, esta tem sido igualmente muito criticada, pelos amis diversos motivos. Entre outros motivos (cf, pe, Scott, 2006) vários autores têm contrariado as suas conclusões, e sobretudo, as suas premissas e metodologias, apontando críticas à sua definição de classe criativa, ao simplismo e limitações várias das metodologias e indicadores utilizados, ao eventual excessivo ênfase nos talentos individuais como factor de desenvolvimento, relegando para segundo plano as empresas e instituições ou um certo optimismo quanto ao potencial do sector criativo, não havendo um alerta quanto a eventuais impactos negativos (Scott, 2006). Resultados empíricos mais recentes, como por exemplo os do projecto ACRE, apresentado mais adiante, desmontam parcialmente parte das dimensões de Florida (cf p.e., Musterd, 2009), mostrando

DINÂMIA'CET - IUL, Centro de Estudos sobre a Mudança Socioeconómica e o Território ISCTE-IUL - Av. das Forças Armadas, 1649-026 Lisboa, PORTUGAL

Tel. 210464031 - Extensão 293100 E-mail: dinamia@iscte.pt www.dinamiacet.iscte.pt 
através de inquéritos à classe criativa/talentos que um dos principais factores de atracção de recursos criativos, à semelhança de outros sectores económicos, continua a ser a oferta de emprego e que, contrariamente ao indicado por Florida, os factores tolerância ou infraestruturas em pouco influem na decisão de localização de um "talento" (não obstante a importância de outros factores "soft" nas decisões de localização).

\section{d) A abordagem de Singapura}

(Heng, Choo e Ho, 2003)

Para além destes três abordagens, mais assentes em desenvolvimentos teóricao-conceptuais e/ou novas metodologias, muitas outras têm sido ensaiadas, com o objectivo de sugerir indicadores que permitam testar em termos práticos a capacidade criativa das cidades, regiões e países, e analisar comparativamente as suas vantagens e desvantagens competitivas em relação a outros espaços. Nessa lógica, assumimos como exemplo um relatório efectuado para o governo de Singapura, numa perspectiva mais "macro" e partindo d e indicadores e metodologias mais convencionais. Este relatório considera dimensões que em muito se cruzam com várias das preocupações das abordagens anteriores, mas que aqui se focam em particular no capital humano e na existência de mercado e de condições institucionais adequadas ao florescimento das indústrias criativas, assentes na exploração de propriedade intelectual.

O relatório "Economic Contributions of Singapore's Creative Industries", da responsabilidade de Heng, Choo e Ho, da Economics Division of Ministry of Trade and Industry de Singapura, aponta assim para a seguinte grelha de análise, com três dimensões e 9 indicadores:

Tabela 4 - Indicadores propostos pelo relatório Economic Contributions of Singapore's Creative Industries (Heng, Choo e Ho, 2003)

\begin{tabular}{|l|l|}
\hline Indicador Proxy & Aspectos medidos pelo indicador \\
\hline $\begin{array}{l}\text { Força de trabalho criativa (capital } \\
\text { humano criativo) }\end{array}$ & - Capacidade de gerar e atrair mais talento criativo; \\
- Diversidade social & - Capacidade actual em termos de trabalho humano \\
- Dimensão da força de trabalho & criativo; \\
criativa & - Qualidade da força de trabalho criativa, medida pela \\
- Capacidade de inovação & sua capacidade e sucesso na aplicação das suas \\
competências à actividade económica.
\end{tabular}

Fonte: elaboração própria, a partir dos autores.

DINÂMIA'CET - IUL, Centro de Estudos sobre a Mudança Socioeconómica e o Território ISCTE-IUL - Av. das Forças Armadas, 1649-026 Lisboa, PORTUGAL

Tel. 210464031 - Extensão 293100 E-mail: dinamia@iscte.pt www.dinamiacet.iscte.pt 
O principal interesse desta abordagem prende-se com o seu pragmatismo. Os indicadores, em menor número e mais facilmente obtíveis junto de fontes estatísticas tradicionais, apresentam por isso uma maior operacionalidade, mas também enfermam de todas as suas limitações, que como se sabe são muitíssimo relevantes no campo das actividades culturais e criativas. No entanto, esta permite uma aplicação alargada a várias cidades ou territórios, e consequentemente a possibilidade de fácil comparabilidade e de benchmarking entre cidades.

Em paralelo, esta metodologia salienta outras dimensões relativamente menosprezadas pelos autores anteriores: o lado da procura ou a existência de mercados (externos e internos), as condições institucionais e uma infraestrutura com capacidade para gerir adequadamente a propriedade intelectual.

\section{e) O Estudo "Creative Economy Report 2008 - The challenge of assessing the creative economy: towards informed policy making" (UNCTAD/UNDP 2008)}

Este estudo da Nações Unidas (promovido pelas suas agências para o comércio internacional e o desenvolvimento, a UNCTAD e o PNUD) procura desenvolver uma medida de benchmarking para a economia criativa que permita posicionar países de diferentes latitudes de acordo com o seu potencial criativo.

Os autores partem da discussão da relevância e robustez dos indicadores mais habituais e possíveis proxies dos mesmos: o emprego, o tempo dispendido em actividades de lazer, o comércio internacional, o valor acrescentado, o copyright e os direitos de propriedade intelectual (DPI), concluindo que, por um lado, todos estes indicadores revelam problemas de fiabilidade e que, por outro lado, atendendo a que a contabilização dos mesmos para todos os países acarretaria custos incomportáveis, será necessário adoptar uma metodologia alternativa com base em indicadores mais fáceis de obter.

A solução proposta pelos autores baseia-se nos indicadores do comércio. As vantagens destes são a sua produção a nível nacional com relativa regularidade, exigindo apenas alguns custos adicionais para uma maior desagregração da informação e a melhoria da qualidade e grau de cobertura a nível nacional. No entanto, à semelhança de outros indicadores para medir criatividade, o cálculo de indicadores do nível de relações comerciais, não é isento de dificuldades, sobretudo decorrentes das dificuldades de cálculo do comércio de serviços, sector que integra a maior parte das indústrias criativas. Com base nestas limitações, o

DINÂMIA'CET - IUL, Centro de Estudos sobre a Mudança Socioeconómica e o Território ISCTE-IUL - Av. das Forças Armadas, 1649-026 Lisboa, PORTUGAL

Tel. 210464031 - Extensão 293100 E-mail: dinamia@iscte.pt www.dinamiacet.iscte.pt 
relatório procura identificar soluções viáveis para o cálculo das transações comerciais de produtos e serviços criativos.

Apesar do indiscutível interesse desta metodologia para comparações nacionais, a mesma não pode (pelo menos facilmente, sem uma reestruturação profunda dos sistemas de contas nacionais, muito centrados na contabilização de fluxos à escala nacional) ser aplicável a uma escala territorial mais reduzida, limitando-se assim a sua operacionalidade.

\section{f) O projecto europeu ACRE - Accommodating Creative Knowledge - Competitiveness of European Metropolitan Regions within the Enlarged Union}

Este projecto liderado pelo Amsterdam Institute for Social Science Research da Universidade de Amsterdão, e envolvendo 13 cidades europeias, investiga o papel dos percursos histórico, económico e geopolítico destas cidades no seu nível actual de criatividade e de conhecimento, bem como o papel dos diversos factores de localização (hard e soft) na criação e estímulo de regiões criativas e, como consequência, as hipóteses teóricas de um determinado território ter maior probabilidade de desenvolver as suas indústrias culturais e criativas.

Este estudo diferencia-se dos anteriores, primeiro pela sua orientação em torno da validação das condições de criatividade e dos factores de localização dos "criativos" mas sobretudo pelo seu carácter empírico. Os indicadores propostos (cf. Tabela 5) foram testados nas cidades participantes tendo sido obtidos resultados muito interessantes no que respeita à verdadeira importância dos vários indicadores na justificação das escolhas de localização dos criativos. Os primeiros resultados deste estudo apontam para a importância crucial dos factores pessoais na escolha de residência dos jovens talentos, tais como os contactos pessoais e, em contrapartida, para a relativa menor importância dos factores "soft" como a abertura ou o grau de tolerância de uma cidade. Outra conclusão, importante num contexto de políticas públicas, é o contributo de instituições públicas de educação e de investigação não apenas para a atracção de novos talentos, mas sobretudo para a sua fixação no território.

DINÂMIA'CET - IUL, Centro de Estudos sobre a Mudança Socioeconómica e o Território ISCTE-IUL - Av. das Forças Armadas, 1649-026 Lisboa, PORTUGAL 
Tabela 5 - Factores de localização do projecto ACRE (Musterd, 2009; ACRE project Website)

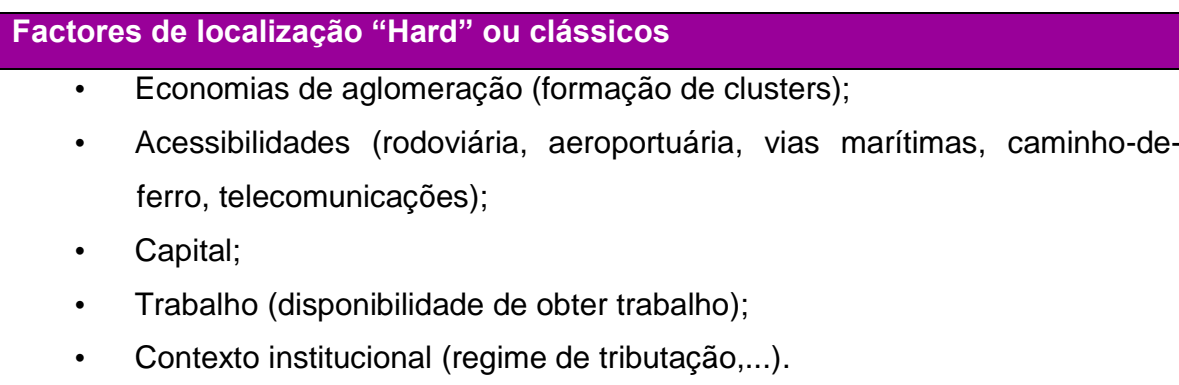
Factores de localização "Soft"

- $\quad$ Atractividade (atmosfera urbana, disponibilidade de alojamento e custo);

- Diversidade;

- Acolhimento;

- Património historico;

- Tolerância;

- Abertura;

- Segurança.

Factores de localização pessoais - redes de contactos

- $\quad$ Naturalidade;

- Família;

- Estudos na cidade;

- Proximidade a amigos.

Fonte: elaboração própria, a partir dos autores.

A principal contribuição deste estudo para a discussão em torno da medição da cratividade e vitalidade urbana prende-se com a combinação da análise do potencial de criatividade de um território tendo por base a sua trajectória de desenvolvimento com o seu potencial actual tendo em atenção a sua capacidade de atracção de novos talentos. Para tal vários indicadores foram testados, dos quais se destaca a consideração de indicadores de natureza pessoal.

Contudo, este estudo centra-se apenas numa versão bastante restrita de actividades, que são assumidas de forma comparativa, de um lado algumas indústrias criativas, nos ramos dos jogos de computador, software, publicações electrónicas, video, cinema, rádio, televisão, arquitectura e serviços empresariais e, no caso das indústrias do conhecimento, nos ramos: serviços empresariais, consultoria jurídica, finanças, I\&D e educação superior. Esta selecção relativamente restrita de ramos coloca-nos algumas dúvidas quanto à possibilidade de extrapolação de resultados para outros ramos criativos, onde os recursos efectivamente se sentirão atraídos por uma maior animação e diversidade cultural e criativa, como é por exemplo o caso de ramos como o design de moda ou do design em geral, bem como das artes propriamente ditas. Finalmente, pelo facto de o estudo ter sido realizado apenas em áreas

DINÂMIA'CET - IUL, Centro de Estudos sobre a Mudança Socioeconómica e o Território ISCTE-IUL - Av. das Forças Armadas, 1649-026 Lisboa, PORTUGAL

Tel. 210464031 - Extensão 293100 E-mail: dinamia@iscte.pt www.dinamiacet.iscte.pt 
urbanas, algum carácter explicativo de certos indicadores poderá não ser válido em cidades de menor dimensão.

\section{Inventário de dimensões de análise e indicadores para a medição do nível de criatividade de um território: um exercício possível}

Apesar de tipologias diferentes, as diversas propostas apresentadas na secção anterior acabam por explorar dimensões relativamente semelhantes.

As abordagens propostas por Landry e Bianchini ou por Matarasso enfatizam um diagnóstico mais voltado para as actividades culturais, a existência de massa crítica e as condições do território ao nível de instalações e espaço público que favoreçam o florescimento de um ambiente vibrante e criativo na cidade. Florida ou o estudo de Singapura exploram outras componentes relevantes, pensando na questão das condições para a promoção activa da atractividade destas actividades, e enfatizando não só as actividades culturais e criativas mais convencionais, mas um leque mais amplo de outras indústrias criativas, com maior componente tecnológica (multimédia, informática) e a exploração da propriedade intelectual. Finalmente, o projecto ACRE, centrado no percurso histórico de um território e nos factores de atracção de talentos, enfatiza outros domínios, como o estabelecimento de redes ou os factores pessoais, impossíveis de validar sem o recurso a inquéritos, e advogando que os factores "soft", salientados sobretudo por Florida, poderão não ser tão determinantes na atracção e na localização de talentos.

Neste quadro, propôs-se como base de trabalho um inventário de indicadores, assente nas listagens propostas nos estudos apresentados e na discussão entre os autores, o mais exaustivo possível, que pudesse configurar uma visão quase "ideal-típica" de um hipotético sistema de informação e monitorização da actividade criativa, a desenvolver localmente num território, havendo disponibilidade e recursos para a sua implementação. Em síntese, considerou-se como ponto de partida, um conjunto de dimensões e indicadores de Inputs; de Outputs e de Resultados (cf. Tabela 6). ${ }^{2}$ Assume-se a escala municipal, no caso português, para este exercício, mas é naturalmente adaptável para outros contextos.

\footnotetext{
2 Esta proposta de indicadores, que se apresenta na tabela 6, foi apresentada como proposta para discussão e potencial implementação a uma autarquia da $A M L$, no âmbito do estudo anteriormente referido (Costa et al, 2010). A sugestão de um conjunto de dimensões e indicadores de Inputs que depois de testados e discutidos com os agentes locais, de forma participada, passaria pela recolha e sistematização dos mesmos pelos serviços técnicos respectivos no sentido de elaborar um índice comparativo dos recursos criativos do concelho, tendo como base de comparação os restantes espaços de referência utilizados na metrópole em que se insere o município. A proposta de dimensões e indicadores de Outputs e Outcomes, também sugeridos para discussão, passaria igualmente por um desenvolvimento e implementação de um sistema de $r$ recolha e tratamento dos dados, no âmbito de um sistema de

DINÂMIA'CET - IUL, Centro de Estudos sobre a Mudança Socioeconómica e o Território ISCTE-IUL - Av. das Forças Armadas, 1649-026 Lisboa, PORTUGAL
}

Tel. 210464031 - Extensão 293100 E-mail: dinamia@iscte.pt www.dinamiacet.iscte.pt 
Tabela 6. Dimensões e indicadores para um sistema exaustivo de monitorização local da actividade criativa num território

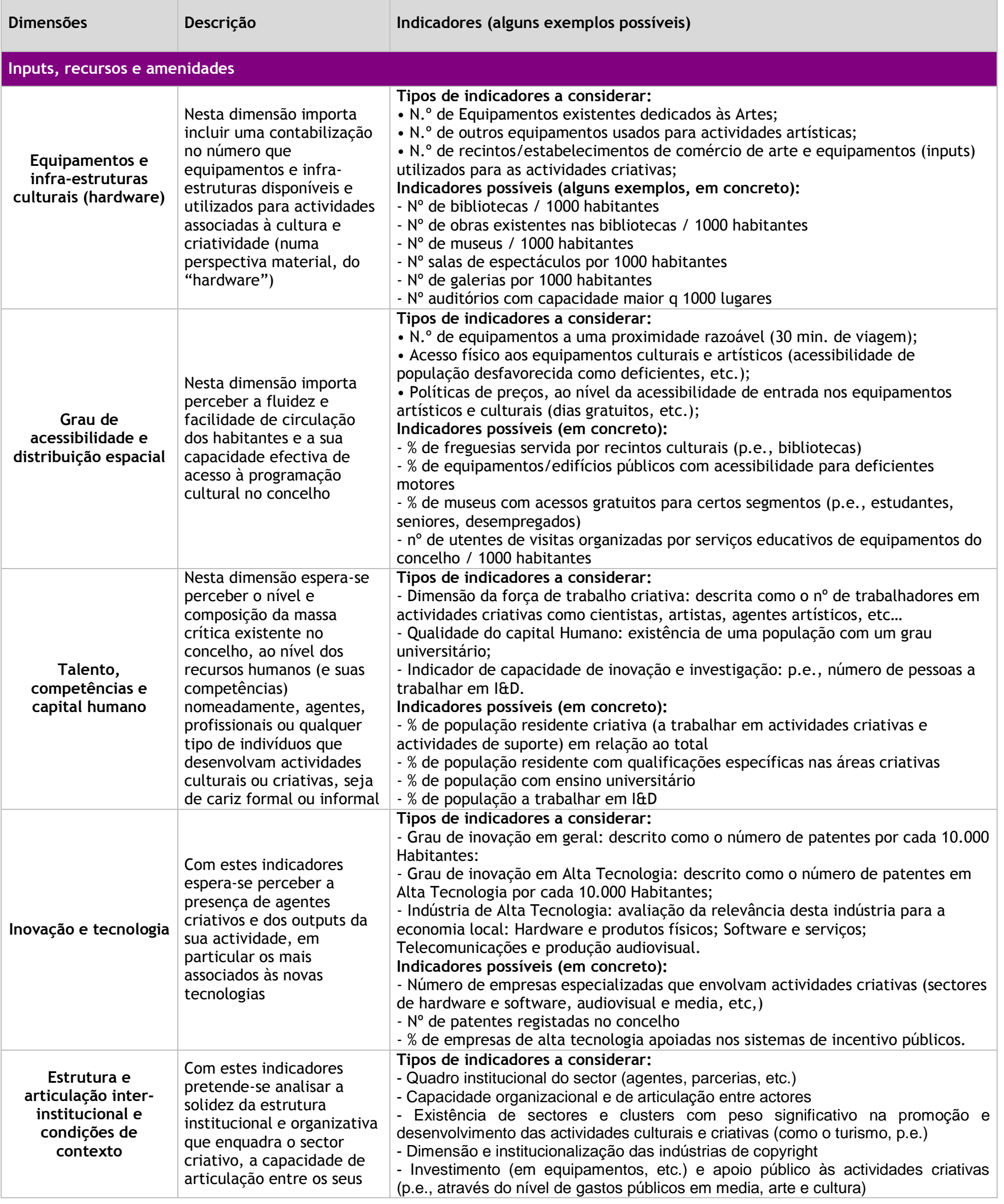

monitorização a desenvolver pela entidade que seria responsável pela promoção e avaliação do sector criativo no concelho.

DINÂMIA'CET - IUL, Centro de Estudos sobre a Mudança Socioeconómica e o Território

ISCTE-IUL - Av. das Forças Armadas, 1649-026 Lisboa, PORTUGAL

Tel. 210464031 - Extensão 293100 E-mail: dinamia@iscte.pt www.dinamiacet.iscte.pt 


\begin{tabular}{|c|c|c|}
\hline & $\begin{array}{l}\text { actores e algumas } \\
\text { condições de contexto que } \\
\text { enquadram a sua actuação. }\end{array}$ & $\begin{array}{l}\text { - condições de contexto ao nível de política fiscal para o sector cultural, sistemas } \\
\text { de apoio ao sector, ou esquemas particulares de financiamento } \\
\text { - condições ao nível do licenciamento das actividades } \\
\text { Indicadores possíveis (em concreto): } \\
\text { - } \mathrm{n}^{\circ} \text { de associações culturais e recreativas por habitante } \\
\text { - } \mathrm{n}^{\circ} \text { de associações e parcerias culturais com envolvimento do município } \\
\text { - peso do sector da hotelaria e restauração na economia local } \\
\text { - } \mathrm{n}^{\circ} \text { de autores registados na SPA/ } \mathrm{n}^{\circ} \text { de autores totais } \\
\text { - Gastos públicos em media, arte e cultura por habitante } \\
\text { - montante de apoio canalizado para o sector por habitante com origem noutros } \\
\text { sectores, por via fiscal (mecenato, jogo,...) } \\
\text { - } \mathrm{n}^{\circ} \text { médio de dias para concessão de uma licença de actividade }\end{array}$ \\
\hline $\begin{array}{c}\text { Diversidade, abertura } \\
\text { e tolerância }\end{array}$ & $\begin{array}{l}\text { Nesta dimensão pretende- } \\
\text { se analisar o grau de } \\
\text { diversidade e } \\
\text { multiculturalidade da } \\
\text { população local, bem como } \\
\text { a sua abertura e tolerância } \\
\text { a novas práticas e } \\
\text { representações (avaliando } \\
\text { indirectamente o nível de } \\
\text { controlo social). }\end{array}$ & 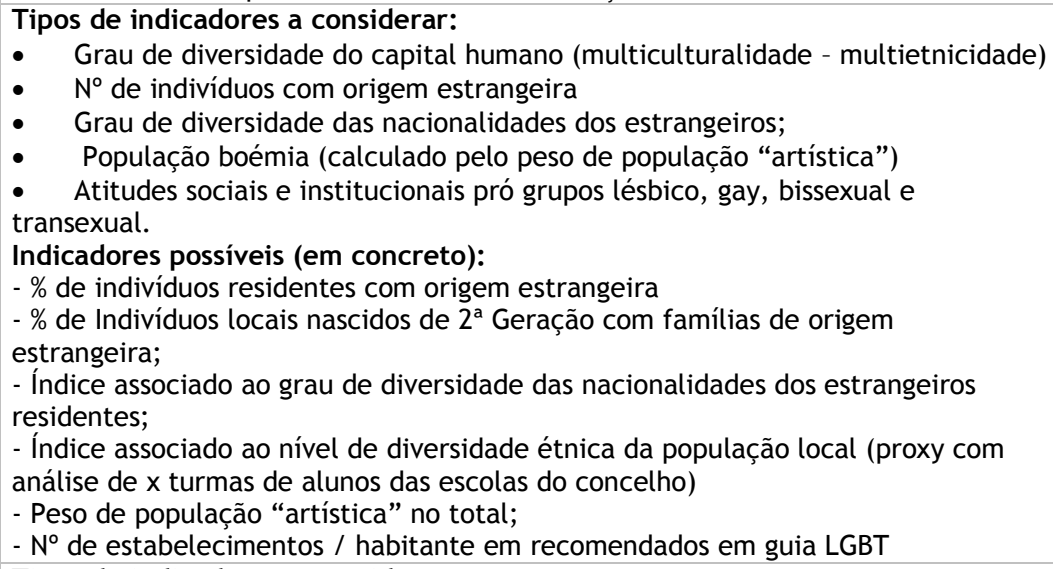 \\
\hline $\begin{array}{c}\text { Mercado } \\
\text { (existência de massa } \\
\text { critica) }\end{array}$ & $\begin{array}{l}\text { Nesta dimensão espera-se } \\
\text { perceber a composição da } \\
\text { massa crítica existente no } \\
\text { concelho em termos de } \\
\text { públicos e de actividades } \\
\text { que tenham como inputs } \\
\text { produtos e serviços } \\
\text { criativos de cariz formal ou } \\
\text { informal, bem como a } \\
\text { existência de mercado } \\
\text { decorrente do investimento } \\
\text { público e privado em } \\
\text { actividades e bens } \\
\text { culturais. }\end{array}$ & $\begin{array}{l}\text { Tipos de indicadores a considerar: } \\
\text { - } \quad \text { Nível de produto per capita e rendimento disponível da população local; } \\
\text { - } \quad \text { Valor acrescentado gerado pelas actividades criativas } \\
\text { - } \quad \text { Nível de crescimento das actividades criativas/conhecimento intensivas; } \\
\text { - } \quad \text { Exportações das indústrias criativas / de copyright } \\
\text { - } \quad \text { Potencial crescimento de públicos para as actividades criativas (com } \\
\text { particular destaque para segmentos jovens, qualificados, etc.) } \\
\text { - } \quad \text { Nível de investimento público em actividades culturais } \\
\text { - } \quad \text { Nível de investimento em arte, patrocínio e doações } \\
\text { Indicadores possíveis (em concreto): } \\
\text { - } \quad \text { PIB per capita (em PPP) do concelho } \\
\text { - Índice do Poder de Compra Concelhio } \\
\text { - } \quad \text { VAB das actividades conhecimento intensivas (ou actividades criativas) } \\
\text { - Tx de crescimento das actividades criativas / conhecimento intensivas } \\
\text { - } \quad \text { Exportação de indústrias copyright (p.e. direitos vendidos) ; } \\
\text { - } \quad \text { \% de habitantes com idade inferior a } 35 \text { anos } \\
\text { - Crescimento da \% de habitantes com qualificações superiores } \\
\text { - Valor investido em arte e cultura pelas autoridades locais / por habitante } \\
\text { (despesas municipais em cultura / habitante); } \\
\text { - Valor investido em arte e cultura no concelho ao nível nacional e regional (p.e } \\
\text { pelo MC ou QREN); } \\
\text { - Valor investido no concelho a título de donativos/mecenato, patrocínios, etc. }\end{array}$ \\
\hline $\begin{array}{l}\text { Capital } \\
\text { Simbólico }\end{array}$ & $\begin{array}{l}\text { Esta dimensão visa revelar } \\
\text { o sentimento de identidade } \\
\text { ou identidades do } \\
\text { concelho, seja a ideia que } \\
\text { os habitantes têm sobre a } \\
\text { imagem do Concelho, seja } \\
\text { a ideia que os de fora têm } \\
\text { sobre o Concelho. }\end{array}$ & $\begin{array}{l}\text { Tipos de indicadores a considerar: } \\
\text { - } \quad \text { Nível de visibilidade do concelho em relação às actividades culturais } \\
\text { - } \quad \text { Nível de notoriedade das actividades culturais do concelho e dos seus agentes } \\
\text { - } \quad \text { Euto-representação e auto-identificação da população local com o concelho; } \\
\text { - } \quad \text { Existência de histórias, lendas, mitos, sobre a Concelho; } \\
\text { sobre o Concelho; } \\
\text { Indicadores possíveis (em concreto): } \\
\text { - No de referências ao concelho em jornais no último mês } \\
\text { - No de referências em guias e programaçães culturais } \\
\text { - No de obras com referências ao concelho (em livros de ficção e/ou obras } \\
\text { cinematográficas) editadas no último ano } \\
\text { - Nível de identificação com o concelho e sua imagem (inquérito) }\end{array}$ \\
\hline \multicolumn{3}{|l|}{$\begin{array}{l}\text { Indicadores de Outputs } \\
\text { (sugestão de indicadores }\end{array}$} \\
\hline $\begin{array}{c}\text { Grau de actividade / } \\
\text { Dinamismo Cultural e } \\
\text { Criativo }\end{array}$ & $\begin{array}{l}\text { Com esta dimensão } \\
\text { pretende-se perceber o } \\
\text { dinamismo cultural e } \\
\text { criativo no concelho, e } \\
\text { averiguar a existência ou }\end{array}$ & $\begin{array}{l}\text { - } \quad N^{\circ} \text { de espectáculos / } 1000 \text { habit. } \\
\text { - } \quad \text { N de exposiçães realizadas / } 1000 \text { habit. } \\
\text { - } \quad \% \text { de despesa em criativa” em relação ao total residente } \\
\text { - } \quad \% \text { de despesa pública em cultura a nível local em relação ao orçamento total }\end{array}$ \\
\hline
\end{tabular}

DINÂMIA'CET - IUL, Centro de Estudos sobre a Mudança Socioeconómica e o Território ISCTE-IUL - Av. das Forças Armadas, 1649-026 Lisboa, PORTUGAL

Tel. 210464031 - Extensão 293100 E-mail: dinamia@iscte.pt www.dinamiacet.iscte.pt 


\begin{tabular}{|c|c|c|}
\hline & $\begin{array}{l}\text { não de um ambiente que } \\
\text { permita gerar dinâmicas } \\
\text { criativas materializadas em } \\
\text { eventos e produtos } \\
\text { concretos }\end{array}$ & $\begin{array}{l}\text { - } \quad \text {. } .^{\circ} \text { de performances, eventos, dias de exibição, workshops, etc. realizados, } \\
\text { em termos absolutos; } \\
\text { - } \quad \text { N. }{ }^{\circ} \text { de novas comissões, produções e trabalhos de arte pública; } \\
\text { - } \quad \text {. } .^{\circ} \text { de visitantes nestes eventos; } \\
\text { - } \quad \text { Capacidade média para os diferentes tipos de actividade; } \\
\text { - } \quad \text { Noporção das actividades que é independente de subsídios; } \\
\text { grupos iniciados ou extintos em cada ano; } \\
\text { - Extensão da participação individual em actividades culturais (p.e., em aulas } \\
\text { ou grupos); }\end{array}$ \\
\hline $\begin{array}{l}\text { Grau de participação } \\
\text { nas actividades } \\
\text { concelhios }\end{array}$ & $\begin{array}{l}\text { Com esta dimensão } \\
\text { pretende-se analisar o } \\
\text { nível de envolvimento da } \\
\text { população nas actividades } \\
\text { culturais e criativas }\end{array}$ & $\begin{array}{ll}\text { - } & N^{\circ} \text { de visitantes a museus concelhios } \\
\text { - } & N^{\circ} \text { de livros requisitados nas bibliotecas do município/habitante } \\
\text { - } & N^{\circ} \text { de espectadores total /1000 habitantes } \\
\text { - } & N^{\circ} \text { de pessoas que frequentaram iniciativas culturais municipais } \\
\text { - } & \text { Tema de ocupação média de equipamentos culturais } \\
\text { - } & N^{\circ} \text { de membros de associações culturais e recreativas / } 1000 \text { habit. }\end{array}$ \\
\hline $\begin{array}{l}\text { Grau de diversidade } \\
\text { dos produtos e da } \\
\text { Actividade cultural }\end{array}$ & $\begin{array}{l}\text { Com esta dimensão } \\
\text { pretende-se analisar o } \\
\text { nível de diversidade e } \\
\text { heterogeneidade cultural } \\
\text { subjacente aos produtos e } \\
\text { actividades culturais e } \\
\text { criativas existentes no } \\
\text { concelho. }\end{array}$ & $\begin{array}{l}\text { - Diferentes tipos de tradições culturais localmente activas (análise documental } \\
\text { e de programações); } \\
\text { - A extensão do apoio público às diferentes formas e expressões culturais } \\
\text { (índice com base na análise de planos de actividades e e orçamentos); } \\
\text { - A composição dos públicos, para diferentes actividades (índice com base em } \\
\text { inquéritos); } \\
\text { - Extensão das ligações e cooperações entre diferentes tradições culturais (p.e., } \\
\mathrm{n}^{\circ} \text { de eventos ou projectos conjuntos); }\end{array}$ \\
\hline $\begin{array}{l}\text { Educação e formação } \\
\text { artística e cultural }\end{array}$ & $\begin{array}{l}\text { Com esta dimensão } \\
\text { pretende-se analisar o grau } \\
\text { de envolvimento da } \\
\text { população em formação no } \\
\text { campo artístico e a } \\
\text { capacidade de o sector } \\
\text { gerar dinâmicas em termos } \\
\text { de qualificação e } \\
\text { competências que } \\
\text { permitam um futuro } \\
\text { desenvolvimento do } \\
\text { cluster, pela via da } \\
\text { dotação em capital } \\
\text { humano. }\end{array}$ & $\begin{array}{l}\text { - } \quad \text { \% de estudantes concelhios inscritos em áreas artísticas/criativas } \\
\text { - } \quad \mathrm{N} .^{\circ} \text { de professores, formadores e profissionais de educação artística; } \\
\text { - Quantidade de actividades artísticas apoiadas através das escolas (em regime } \\
\text { - } \quad \text { Natricular ou extra curricular); } \\
\text { n. }{ }^{\circ} \text { de pessoas a estudar para qualificações artísticas; } \\
\mathrm{N}^{\circ} \text { (per capita) de cursos livres e não conferentes de grau (públicos/privados) } \\
\text { realizados anualmente no concelho em áreas culturais e criativas; } \\
\text { - Envolvimento na educação pelas organizações artísticas do sector público (\% } \\
\text { população coberta por serviços educativos de museus); }\end{array}$ \\
\hline $\begin{array}{c}\text { Grau de } \\
\text { mercantilização, } \\
\text { profissionalização, } \\
\text { organização e } \\
\text { empreendedorismo } \\
\text { (nas entidades } \\
\text { criativas) }\end{array}$ & $\begin{array}{l}\text { Com esta dimensão } \\
\text { pretende-se analisar o } \\
\text { nível de profissionalização } \\
\text { e organização das } \\
\text { actividades e instituições } \\
\text { do sector cultural e } \\
\text { criativo bem como a } \\
\text { propensão para o } \\
\text { empreendedorismo e a } \\
\text { exploração do potencial de } \\
\text { mercado destas actividades }\end{array}$ & 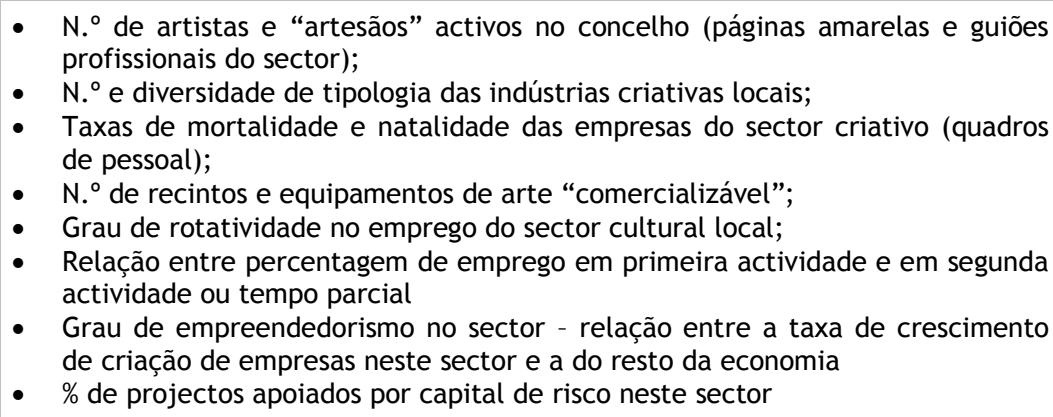 \\
\hline $\begin{array}{l}\text { Desenvolvimento da } \\
\text { infra-estrutura } \\
\text { organizacional e } \\
\text { institucional de apoio } \\
\text { ao sector e das } \\
\text { condições de } \\
\text { contexto }\end{array}$ & $\begin{array}{l}\text { Com esta dimensão } \\
\text { pretende-se perceber a } \\
\text { existência de instituições } \\
\text { de promoção das práticas } \\
\text { culturais e criativas e de } \\
\text { regulação dos seus direitos } \\
\text { de propriedade bem com a } \\
\text { capacidade de articulação } \\
\text { inter-institucional no } \\
\text { sector }\end{array}$ & 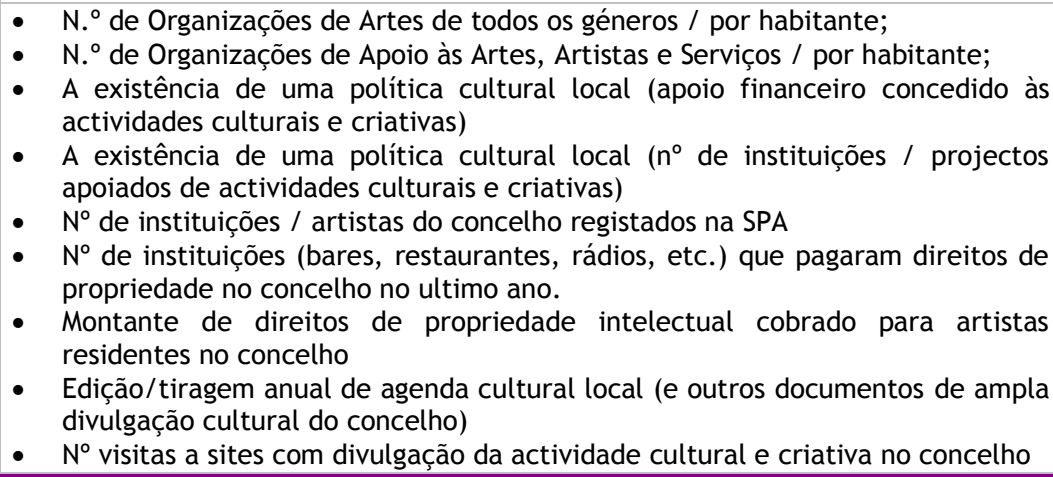 \\
\hline \multicolumn{3}{|c|}{$\begin{array}{l}\text { Indicadores de Outcomes / Resultados } \\
\text { (sugestão para discussão entre os stakeholders locais e com a entidade responsável pela monitorização dos resultados) }\end{array}$} \\
\hline $\begin{array}{l}\text { Desenvolvimento } \\
\text { individual }\end{array}$ & $\begin{array}{l}\text { Com esta dimensão } \\
\text { pretende-se avaliar os } \\
\text { impactos na qualidade de }\end{array}$ & $\begin{array}{l}\text { - } \quad \text { Reforço dos níveis de auto confiança; } \\
\text { - } \quad \text { Vida social mais activa; } \\
\text { - } \quad \text { Maior envolvimento nas actividades da comunidade; }\end{array}$ \\
\hline
\end{tabular}

DINÂMIA'CET - IUL, Centro de Estudos sobre a Mudança Socioeconómica e o Território ISCTE-IUL - Av. das Forças Armadas, 1649-026 Lisboa, PORTUGAL

Tel. 210464031 - Extensão 293100 E-mail: dinamia@iscte.pt www.dinamiacet.iscte.pt 


\begin{tabular}{|c|c|c|}
\hline & $\begin{array}{l}\text { vida individual dos } \\
\text { munícipes de Cascais do } \\
\text { desenvolvimento do } \\
\text { potencial associado aos } \\
\text { recursos criativos }\end{array}$ & $\begin{array}{l}\text { - } \quad \text { Aproveitamento da formação na comunidade; } \\
\text { - } \quad \text { Aproveitamento da formação vocacional e da educação; } \\
\text { - } \quad \text { Valorização da auto-imagem e auto-representações; } \\
\text { - } \quad \text { Reforço do entendimento dos direitos e das responsabilidades; } \\
\text { - } \quad \text { Identificação de novas capacidades; } \\
\text { - } \quad \text { Criação de emprego e auto-emprego; }\end{array}$ \\
\hline $\begin{array}{l}\text { Desenvolvimento da } \\
\text { comunidade }\end{array}$ & $\begin{array}{l}\text { Com esta dimensão } \\
\text { pretende-se avaliar os } \\
\text { impactos na qualidade de } \\
\text { vida geral da comunidade } \\
\text { local, resultantes do } \\
\text { desenvolvimento do } \\
\text { potencial associado aos } \\
\text { recursos criativos }\end{array}$ & $\begin{array}{l}\text { - } \quad \text { Contacto inter-geracional; } \\
\text { - } \quad \text { Cooperação intra-comunitária; } \\
\text { - } \quad \text { Aumento da utilização do centro da cidade; } \\
\text { - } \quad \text { Empowerme da sensação de segurança; } \\
\text { - } \quad \text { No de pessoas envolvidas em actividades da comunidade; } \\
\text { - } \quad \text { Desenvolvimento de capacidades e competências organizativas; } \\
\text { - } \quad \text { Desenvolvimento de novos projectos comunitários; } \\
\text { - } \quad \text { Participação da população nas consultas locais; } \\
\text { - } \quad \text { Melhoria na imagem dos bairros; } \\
\text { - } \quad \text { Audiência das actividades artísticas; } \\
\text { - } \quad \text { Reforço da sensação de bem-estar pessoal; } \\
\text { - } \quad \text { Apoio a grupos vulneráveis; } \\
\text { - } \quad \text { Valorização do trabalho voluntário; }\end{array}$ \\
\hline
\end{tabular}

Fonte: elaboração própria, no âmbito do projecto efectuado para uma autarqui da AML (Costa et al, 2010)

\section{Uma proposta operativa de dimensões de análise e indicadores para a medição do nível de criatividade de um território}

Apesar do valor indiscutível de se constituir uma lista o mais exaustiva possível de indicadores de dinamismo cultural e criativo, como a que se sugere na secção anterior, em termos práticos dificilmente será possível constituir uma base de dados para diagnóstico ou para monitorização da criatividade/vitalidade de um território para os vários indicadores e actualizá-la regularmente, a não ser com uma estrutura técnica dedicada, consideráveis recursos e meios disponíveis, e vontade política considerável. Em termos pragmáticos, dificilmente se atingirá tal objectivo no curto prazo.

Neste sentido, procurámos identificar um conjunto mais limitado de indicadores-chave, seguindo o princípio "SMART", atrás já referido, sobretudo tendo em conta os aspectos "Especificidade" e "Relevância" para a medição da criatividade/vitalidade de um território; a "Disponibilidade" e a "Mensurabilidade" de informação estatística ao nível local e finalmente a possibilidade de proceder a comparações internacionais (universalidade do indicador).

O primeiro passo foi a eliminação de indicadores não disponíveis e não mensuráveis, o que afecta sobretudo as dimensões "Desenvolvimento individual" e "Desenvolvimento da comunidade" no campo dos resultados. Posteriormente, solicitou-se à equipa do projecto de investigação CreatCity que com base na experiência do trabalho de campo identificasse os indicadores mais relevantes, até um máximo de 20 indicadores, incluindo, dentro do possível, pelo menos um indicador por dimensão (cf. Tabela 6). Os resultados desta discussão reflectemse na lista seguinte. 
Não sendo naturalmente a solução ideal, representa um esforço de compromisso com as características essenciais a um sistema exequível e facilmente aplicável, que assegure uma mínima garantia de qualidade ao processo de medição, monitorização e comparabilidade da actividade criativa para um determinado território.

Tabela 7. Lista sintética de indicadores de criatividade/vitalidade de um território, a partir da reflexão e selecção com base em inquérito aos membros da equipa do projecto

Creatcity

\begin{tabular}{|c|c|}
\hline Dimensões & Indicadores \\
\hline \multicolumn{2}{|l|}{ Indicadores de Input } \\
\hline \multirow{2}{*}{$\begin{array}{l}\text { Equipamentos e infra-estruturas } \\
\text { culturais (hardware) }\end{array}$} & № salas de espectáculos por 1000 habit. \\
\hline & - $\quad$ № de galerias por 1000 habit. \\
\hline $\begin{array}{l}\text { Talento, competências e capital } \\
\text { humano }\end{array}$ & $\begin{array}{l}\text { - Dimensão da força de trabalho criativa: descrita como o no de trabalhadores em } \\
\text { actividades criativas como cientistas, artistas, agentes artísticos, etc. }\end{array}$ \\
\hline Inovação e tecnologia & $\begin{array}{l}\text { - Número de empresas especializadas que envolvam actividades criativas } \\
\text { (sectores de hardware e software, audiovisual e media, etc,) }\end{array}$ \\
\hline \multirow{2}{*}{$\begin{array}{l}\text { Estrutura e articulação inter- } \\
\text { institucional e condições de contexto }\end{array}$} & - $\quad$ № de associações culturais e recreativas por 1000 habit. \\
\hline & - $\quad$ Gastos públicos em media, arte e cultura por habitante \\
\hline Diversidade, abertura e tolerância & $\begin{array}{l}\text { - População "boémia" (calculado pelo peso de população "artística"): Peso de } \\
\text { população "artística" no total }\end{array}$ \\
\hline \multirow{3}{*}{ Mercado } & - $\quad$ Tx de crescimento das actividades criativas / conhecimento intensivas \\
\hline & $\begin{array}{l}\text { - Potencial crescimento de públicos para as actividades criativas (com particular } \\
\text { destaque para segmentos jovens, qualificados, etc.) - \% de habitantes com } \\
\text { idade inferior a } 35 \text { anos }\end{array}$ \\
\hline & $\begin{array}{l}\text { Valor investido em arte e cultura pelas autoridades locais / por habitante /por } \\
\text { ano (despesas do território em cultura / habitante); }\end{array}$ \\
\hline Capital Simbólico & $\begin{array}{l}\text { - №. de referências a actividades culturais/criativas do território em jornais nos } \\
\text { últimos } 3 \text { meses }\end{array}$ \\
\hline \multicolumn{2}{|l|}{ Indicadores de Output } \\
\hline $\begin{array}{l}\text { Grau de actividade / Dinamismo } \\
\text { Cultural e Criativo }\end{array}$ & $\begin{array}{l}\text { - } \quad{ }^{\circ}{ }^{\circ} \text { de espectáculos (música, teatro,...)/ } 1000 \text { habit durante } 1 \text { mês } \\
\text { representativo (p.e., fora de período de férias) }\end{array}$ \\
\hline Grau de participação nas actividades & $\begin{array}{l}\text { - } \quad \text { ․o de pessoas que frequentaram iniciativas culturais em equipamentos } \\
\text { públicos durante um mês representativo } / 1000 \text { hab. }\end{array}$ \\
\hline $\begin{array}{l}\text { Grau de diversidade dos produtos e da } \\
\text { actividade cultural }\end{array}$ & $\begin{array}{l}\text { - } \quad \text { ․o de eventos alternativos durante um mês representativo /1000 hab. (música } \\
\text { independente, danca, cinema de autor, exposições não mainstream...) }\end{array}$ \\
\hline $\begin{array}{l}\text { Educação e formação artística e } \\
\text { cultural }\end{array}$ & $\begin{array}{ll}\text { - } & \% \text { de estudantes do ensino superior inscritos em cursos artísticos/criativos } \\
\text { - } & \quad \mathrm{N} . \text { o de professores, formadores e profissionais de educação artística } \\
\end{array}$ \\
\hline $\begin{array}{l}\text { Grau de mercantilização, } \\
\text { profissionalização, organização e } \\
\text { empreendedorismo (nas entidades } \\
\text { criativas) }\end{array}$ & N.$^{\circ}$ de artistas e "artesãos" activos no território \\
\hline $\begin{array}{l}\text { Desenvolvimento da infra-estrutura } \\
\text { organizacional e institucional de apoio } \\
\text { ao sector e das condições de contexto }\end{array}$ & $\begin{array}{ll}- & \quad N .^{\circ} \text { de organizações de artes de todos os géneros / por habitante } \\
\text { - } & \text { Edição/tiragem anual de agendas culturais do território (e outros documentos } \\
\text { de ampla divulgação cultural do território) }\end{array}$ \\
\hline \multicolumn{2}{|l|}{ Indicadores de Resultado } \\
\hline Desenvolvimento da comunidade & $\begin{array}{l}\text { - } \quad \text { N.o Projectos de criatividade com a população infantil-juvenil/população infantil- } \\
\text { juvenil }\end{array}$ \\
\hline
\end{tabular}

DINÂMIA'CET - IUL, Centro de Estudos sobre a Mudança Socioeconómica e o Território ISCTE-IUL - Av. das Forças Armadas, 1649-026 Lisboa, PORTUGAL

Tel. 210464031 - Extensão 293100 E-mail: dinamia@iscte.pt www.dinamiacet.iscte.pt 


\section{CONCLUSÕES E RECOMENDAÇÕES}

A selecção de um conjunto de indicadores apresenta sempre um certo risco decorrente sobretudo da possível exclusão de dimensões relevantes ou da definição dos próprios indicadores. No nosso caso, a procura de uma lista operacionalizável fez-se em detrimento da inclusão de indicadores de carácter mais qualitativo, certamente mais interessantes para uma abordagem mais holística e rigorosa, mas de difícil e onerosa recolha e tratamento.

Os indicadores qualitativos são na maior parte dos casos indicadores de resultados (p.e., reforço dos níveis de autoconfiança,contacto inter-geracional ou aumento da sensação de segurança), normalmente mais dificeis ou mesmo impossíveis de obter e/ou com maiores custos associados à sua obtenção (p.e., dados apenas obtíveis através de inquérito ou outra forma de recolha massiva de informação).

Uma outra limitação da nossa proposta prende-se com a própria descrição dos indicadores. Embora a maior parte dos mesmos pareça à partida relativamente evidente quanto ao seu significado, na realidade a sua aplicação determinaria um trabalho adicional de definição e "normalização" de cada indicador, envolvendo uma descrição detalhada dos conceitos associados, desde conceitos básicos como "população artística", "arte", "cursos artísticos/criativos", até conceitos provavelmente menos consensuais como "eventos alternativos". A precisão dos indicadores seria fundamental, quer para facilitar o trabalho da(s) pessoa(s) envolvida(s) na colecta e tratamento de dados, quer sobretudo para facilitar comparações supra-territoriais.

Importa ainda notar que, embora os autores procurassem obter no seio da equipa um conjunto de indicadores mais ou menos consensual, seguindo as orientações dadas pelos autores desta reflexão, na realidade, exepto no caso de indicadores indiscutíveis (p.e., emprego no sector cultural e criativo), a selecção e a prioritização de dimensões de análise gerou bastante discussão, e assumiu uma variedade demposições muito considerável, reflectindo a questão ainda não esclarecida (e não facilemnte consensualizável, dada a sua natureza) de como medir as actividades culturais e criativas e de quais as facetas mais relevantes destas actividades. Esta última questão levanta de novo o problema dos objectivos associados à identificação de indicadores de criatividade, apenas se podendo concluir que objectivos distintos poderão determinar baterias de indicadores igualmente distintas. Neste sentido, é fundamental que os utilizadores deste instrumento não o considerem nunca como estático ou definitivo, mas que reflictam sobre o seu objectivo e que o adaptem às necessidades específicas do território em causa.

Não obstante todas limitações apontadas, e atendendo ao panorama actual de quantificação das actividades criativas, inexistente ou baseado num conjunto muito reduzido de 4 ou 5 
indicadores, acreditamos no entanto que a nossa proposta possa efectivamente dotar, sobretudo, os actores ao nível local ou regional, de um instrumento interessante, e facilmente operacionalizável, para avaliarem o seu potencial criativo e a sua evolução ao longo do tempo, sobretudo para aqueles que se movem num contexto directo de intervenção no terreno de suporte a estas actividades e de promoção e avaliação de política públicas.

De forma a aumentar a operacionalidade e a sustentabilidade deste conjunto de indicadores, sugerimos ainda que se identifique uma sub-lista de indicadores de acordo com as especificidades e com as necessidades inerentes a cada território em causa com cada implementação. Dessa forma, e com a circulação da informação respectiva, seria possível efectuar confrontos e actualizações regulares destas listas (tanto sub-listas, como a lista mais extensa) por entre a comunidade de investigadores e técnicos interessados na problemática da operacionalização da capacidade criativa e cultural das cidades. 


\section{REFERÊNCIAS BIBLIOGRÁFICAS}

COSTA, P. (2007), A cultura em Lisboa: competitividade e desenvolvimento territorial, Lisboa: Imprensa de Ciências Sociais.

COSTA, P. (Coord.) (2010), Cascais Criativo: Estudo sobre o potencial de desenvolvimento de Cascais com base nas indústrias criativas - Relatório Final, Dezembro de 2010, Cascais: DINÂMIA-CET - Câmara Municipal de Cascais.

COSTA, P.; SEIXAS, J; e ROLDÃO, A. (2009), “From 'creative cities' to 'urban creativity’? Space, creativity and governance in the contemporary city", Dinâmia Working Paper $\mathrm{n}^{\mathrm{o}}$ 2009/80.

COSTA, P.; MAGAlhães, M., VASCONCElos, B. e SUGAHARA, G. (2008), "On 'Creative Cities' governance models: a comparative approach", The Service Industries Journal , Vol. 28, n³-4, April-May 2008, pp. 393-413.

COSTA, P.; MAgAlhães, M., VASCONCElOS, B. e SUgAHARA, G. (2007), "A discussion on the governance of 'Creative Cities': Some insights for policy action", Norwegian Journal of Geography Vol.61, pp.122-132, Oslo.

COSTA, P.; VASCONCELOS, B. e SUGAHARA, G.. (2007a), "O meio urbano e a génese da criatividade nas actividades culturais", in "Recriar e valorizar o território", Actas do $13^{\circ}$ congresso da APDR, Açores, 5-7 Julho 2007; Coimbra: APDR.

DCMS (1998). Creative Industries Mapping Document. London, Department of Culture, Media and Sports.

DCMS (2006), Evidence and Analysis: Final Report. Creative Economy Programme, Department of Culture, Media and Sport.

FLORIDA, R. (2000), The rise of the creative class, and how it is transforming work, leisure, community and everyday life, Basic Books, New York.

FLORIDA, R., TINAGLI, I. (2004), Europe in the Creative Age, Carnegie Mellon Software Industry Publishing/Demos.

DINÂMIA'CET - IUL, Centro de Estudos sobre a Mudança Socioeconómica e o Território ISCTE-IUL - Av. das Forças Armadas, 1649-026 Lisboa, PORTUGAL 
GIBSON, C. (2004), Cultural industry production in remote places: indigenous popular music in Australia, In POWER, D. and SCOTT, A. (Ed.), The cultural industries and the production of culture, London and New York, Routledge.

GIBSON, K. (2005), Cultural economy: a critical review, Progress in Human Geography, 29(5), pp.541-561.

GRAVARI-BARBAS, M., VIOLIER, P. (eds.) (2003). Lieux de culture, culture des lieux. Prodution(s) culturelle(s) locale(s) et émergence des lieux: dynamiques, acteurs, en jeux. PUR, Rennes.

HALL, P. (2000) Creative cities and economic development, in Urban Studies, 37 (4), 639-649.

HENG, T.; CHOO, A.; HO T. (2003), "Economic Contributions of Singapore's Creative Industries". Economic Survey Of Singapore First Quarter 2003. Singapore, Creative Industries Strategy Group Ministry of Information, Communications and the Arts, Economics Division Ministry of Trade and Industry.

INTERARTS, EFAH, FEAP (2003), Study on Cultural Cooperation in Europe, EC/ DirectorateGeneral for Education and Culture.

HARTLEY, J. (2005) Creative industries, Blackwell, London.

KEA/EC (2006), Economy of culture in Europe, EC-DG Education and Culture.

LANDRY, C. e BIANCHINI, F. (1994) The Creative City - Working Paper 3: Indicators of a Creative City. A Methodology for assessing Urban Viability and Vitality, Comedia, Gloucestershire.

LANDRY, C. (2003), The creative city. A toolkit for urban innovators, Earthscan, London.

MARSHALL, N. (2007), Methodological Pitfalls in Social Network Analysis - Why current methods produce questionable results, VDM Verlag Dr, Müller, Saarbrücken.

MATARASSO (1999), “Towards a Local Culture Index - Measuring the cultural vitality of communities", Comedia.

MONTGOMERY, J. (2005), Beware 'the creative class' creativity and wealth creation revisited in Local Economy, 20 (4), 337-343. 
MUSTERD, S. (2009), “'Soft', 'Hard', and 'Network' Conditions for 'Creative Knowledge Cities", presentation to the Creatcity International Seminar "From 'Creative Cities' to 'Urban Creativity"”, Lisbon, ICS/UL, 10 December 2009.

NESTA (2006), Creating growth, how the UK can develop world class creative business, Report, NESTA.

OECD (2005), “Culture and Local Development”, Paris: OECD.

OECD (2006), International Measurement of the Economic and Social Importance of Culture, www.oecd.org/dataoecd/26/51/37257281.pdf,

RATO, B.; MÜHLHAN, O., ROLDÃO, A. (2009), A typology of creative cities in the world lessons learned, Paper presented to the 8th International Symposium of the International Urban Planning and Environment Association.

SCOTT, A.J. (2006), Creative cities - Conceptual issues and policy questions in Journal of Urban Affairs, 28 (1), pp. 1-17.

SCOTT, A. J. (2007), Capitalism and Urbanization in a New Key? The Cognitive-Cultural Dimension, Social Forces, 85(4).pp. 1465-1482.

SCOTT, A. J. (2003), The cultural economy of cities, Sage, London.

SCOTT, J. (1991), Social Network Analysis: A Handbook, SAGE, London.

SIMON, F. and E. VERHAGEN (2006), Creativity and the City - How the creative economy is changing the city, NAi Publishers, Amsterdam.

THROSBY, C. D. (2001). Economics and Culture, Cambridge University Press, Cambridge.

TINAGLI, I., FLORIDA, R., STROM, P. and WAHLQVIST, E (2007), "Sweden in the Creative Age", Creativity Group Europe and School of Business, Economics and Law, Göteborg University.

UNCTAD/UNDP (2008), "Creative Economy Report 2008 - The challenge of assessing the creative economy: towards informed policy making".

Websites: ACRE: http://acre.socsci.uva.nl/

DINÂMIA'CET - IUL, Centro de Estudos sobre a Mudança Socioeconómica e o Território ISCTE-IUL - Av. das Forças Armadas, 1649-026 Lisboa, PORTUGAL Tel. 210464031 - Extensão 293100 E-mail: dinamia@iscte.pt www.dinamiacet.iscte.pt 